\title{
Photoluminescence dosimetry : the alternative in personnel monitoring
}

\author{
E. PIESCH, B. BURGKHARDT*
}

(Manuscrit reçu le 10 mars 1993)

ABSTRACT A new full automatic PLD system, consisting of a one-element photoluminescent glass and the readout system Toshiba FGD-10, is now commercially available, PTB type tested and introduced into routine monitoring. Mainly because of its glass specific dosimetric properties, the PLD system was found to be superior to film dosemeters and TLD systems. Under the aspect of routine application, the paper discusses the dosimetry system using pulsed UV-laser excitation and the dosimetric properties, such as energy and angular response, random uncertainty and ambient parameters affecting the dose measurement. The main advantages are the low pre-dose of $(30 \pm 1) \mu \mathrm{Sv}$ of annealed glasses, the low coefficient of variation of $2 \%$ at $0.1 \mathrm{mSv}$ which allows to measure doses above $10 \mu \mathrm{Sv}$, the long-term stability of the dose measurement of about $1 \%$, the optimised energy and angular response for the simultaneous indication of different dose quantities such as exposure $X$ free in air or $H_{\mathrm{p}}(10)$ on a slab phantom in an energy range of $12 \mathrm{keV}-1.3 \mathrm{MeV}$. In comparison with other dosimetry systems the results of the patten approval and the participation to an IAEA intercomparison for personnel dosimeters as well as the results of routine monitoring confirm the progress in photolumenescence dosimetry and the precision of measurement also under elevated ambient temperature within individual and environmental monitoring.

RÉSUMÉ Un nouveau dispositif de dosimétrie par photoluminescence (PLD), entièrement automatique, constitué d'un verre photoluminescent à un élément et du système de lecture Toshiba FGD-10, est désormais commercialisé. Il a été testé au Physikalisch-Technische Bundesanstalt (PTB) et introduit en surveillance de routine. En raison, avant tout, des propriétés dosimétriques spécifiques de son verre, le dispositif PLD s'est avéré supérieur aux dosimètres photographiques ou thermoluminescents. Sont discutés, ici, du point de vue de l'application en routine, le dispositif de dosimétrie utilisant l'excitation par laser-UV pulsé et ses propriétés dosimétriques - énergie et réponse angulaire, incertitude aléatoire et paramètres d'ambiance affectant la mesure de la dose. Les principaux avantages sont la faible pré-dose $(30 \pm 1 \mu \mathrm{Sv})$ des verres recuits, le faible coefficient de variation $(2 \%$ à $1 \mathrm{mSv})$ qui permet la mesure de doses supérieures à $10 \mu \mathrm{Sv}$, la stabilité à long terme des doses mesurées (environ 1\%), la réponse en fonction de l'énergie et la réponse angulaire pour l'indication simultanée de différentes grandeurs dosimétriques (par ex. $\boldsymbol{X}$ en espace libre ou $\boldsymbol{H}_{\mathrm{p}}(10)$ sur fantôme plaque dans le domaine d'énergie de $12 \mathrm{keV}$ à $1,3 \mathrm{MeV}$. Comparés à d'autres dispositifs, les résultats des tests d'homologation et la participation à une intercomparaison de dosimètres individuels, sous l'égide de l'Agence internationale de l'énergie atomique (AIEA) d'une part et d'autre part l'utilisation en routine confirment les progrès de la dosimétrie par photoluminescence et la précision de la mesure même par température ambiante élevée dans le cadre de la surveillance individuelle ou de l'environnement.

* Kernforschungszentrum Karlsruhe (KfK) GmbH, Hauptabteilung Sicherheit/Dosimetrie Postfach 3640 , D-76021 Karlsruhe, Germany. 


\section{Introduction}

For more than 25 years photoluminescent glass dosemeters have been applied at the KfK dosemeter service in a large-scale use within personnel and environmental monitoring $[10,14]$. In the past, one of the major limiting factors of photoluminescence dosimetry (PLD) was, however, the significance of pre-dose and thus the inaccuracy in the measurement of small doses at levels of $0.1 \mathrm{mSv}$. First observations with pulsed UV-laser excitation by Kastner in 1967 showed that differences in the decay time constant may be used to separate the pre-dose component of the signal [12]. Further studies in the $1970 \mathrm{~s}$ created the basis for a better evaluation technique of glasses and a pre-dose reduction by a factor of 10 [2, 8-9, 22-23]. The project of developing a modern, fully automatic readout system then became reality in the middle of the $80 \mathrm{~s}$, when pulsed UV-laser tubes of high intensity were available $[4,13,15,17]$.

The actual progress in the field of photoluminescence dosimetry and thus the breakthrough of a so far unattractive technique is based on a modern evaluation technique using pulsed UV-laser excitation and a fully automatic readout. After an extensive development cooperation with Toshiba Glass, the commercially available system Toshiba FGD-10 was type tested at the Physikalisch-Technische Bundesanstalt in Braunschweig (PTB) [1]. In Germany, this pattern approval is the legal basis for the use of dosemeters in personnel monitoring. Before starting with a large scale application at KfK, about 6000 dosemeters have been introduced into routine monitoring. The capability of the PLD system was recently demonstrated at the IAEA Intercomparison for individual dosemeters [18-19]. First experiences in long-term routine monitoring are now available [20], so that the PLD system is ready to act as a routine system in individual and area monitoring measuring simultaneously both the exposure free in air and the new ICRU quantities such as $H_{\mathrm{p}}(10)$ in personnel monitoring [11].

The first experiences with the commercial PLD system Toshiba FGD-10 and the flat one-element glass dosemeter confirm the essential advantages and attractive features of photoluminescence dosimetry such as the intrinsic suppression of the pre-dose resulting in a low value and scatter of pre-dose, the low coefficient of variation in the dose range of 10 to $100 \mu \mathrm{Sv}$ and the longterm stability of readout. In comparison to thermoluminescence (TL) and film dosimetry it is evident that today phosphate glass dosimetry seems to be superior in its dosimetric properties.

\section{UV excitation and intrinsic pre-dose suppression resulting in low pre-doses}

The dosimetry using the photoluminescence of silver activated metaphosphate glasses is based on the formation of fluorescence centers during exposure with ionizing radiation. When exposed to UV light, irradiation-induced fluores- 
cence light is emitted, the intensity of which is proportional to the dose (Fig. 1). In the reader different optical filters are used to separate the additional intrinsic photoluminescence intensity from the required signal. The overlapping of both effects in the wave length range above $550 \mathrm{~nm}$ results, however, in a so called pre-dose of unirradiated glasses which, for conventional UV excitation, was found to be in the order of $1 \mathrm{mSv}$ for annealed glasses $\left(400^{\circ} \mathrm{C}, 1 \mathrm{~h}\right)$. Due to the silver content which is responsible for the formation of fluorescence centers and the high absorption of low energy photons, energy compensation filters are necessary to flatten the energy response. For unshielded glasses of the Toshiba FD-1 type, the maximum response at about $40 \mathrm{keV}$ is a factor of 6 , for the new FD-7 glass a factor of 3.6 higher than that for ${ }^{137} \mathrm{Cs}$ photons.

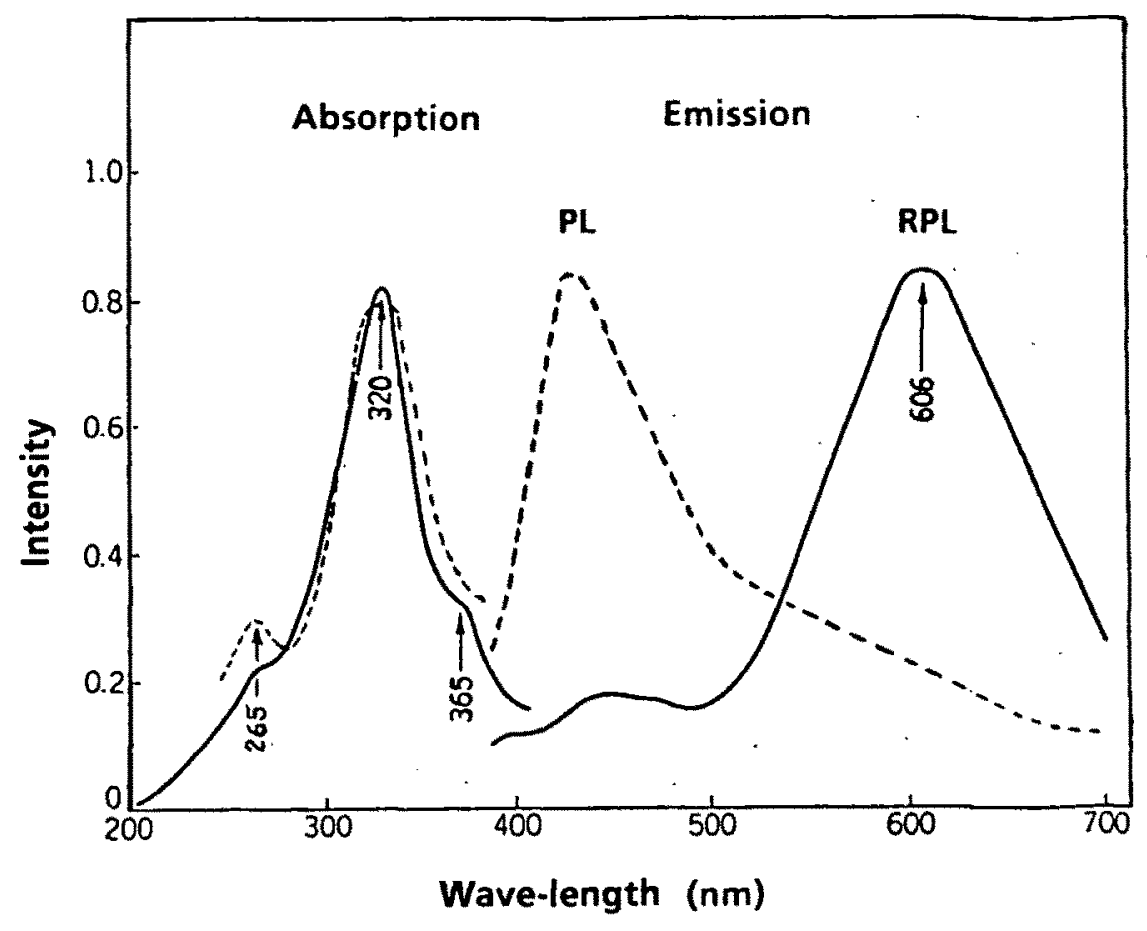

Fig. 1. - Absorption of light and the following emission of photoluminescence (PL) and radiation-induced photoluminescence (RPL) in silver activated phosphate glass.

Absorption de la lumière et émission de photoluminescence (PL) et de photoluminescence radioinduite (RPL) dans le verre au phosphate activé à l'argent.

During the pulsed UV-laser excitation, the intrinsic individual pre-dose of glasses is simultaneously measured together with the radiation induced reading. Figure 2 shows typical PL intensity curves $I(t)$ of an annealed and an irradiated glass, respectively, immediately after UV-pulse excitation of 4 ns. The time dependent PL intensity $I(t)$ is integrated in two different periods, namely the radiation independent long-term component of the residual reading in the period 2 between $40-45 \mu$ s and the short-term component in the period 1 between 2-7 $\mu \mathrm{s}$. A multiple $f_{\mathrm{ps}}$ of the measured residual dose is subtracted from the total reading resulting in the radiation induced reading $M$. The pre-dose suppression factor $f_{\mathrm{ps}}$ is measured once after the first annealing. In order to 
exclude negative readings due to the uncertainty of measurement, the $f_{\mathrm{ps}}$ factor was chosen by definition to indicate a pre-dose of about $30 \mu \mathrm{Sv}$. The frequency distribution of the pre-dose in Figure 3 shows that the pre-dose setting is conservative and could be reduced in principle to a value of $10 \mu \mathrm{Sv}$, taking into account that one digit of the indicated readout corresponds to $1 \mu \mathrm{Sv}$.
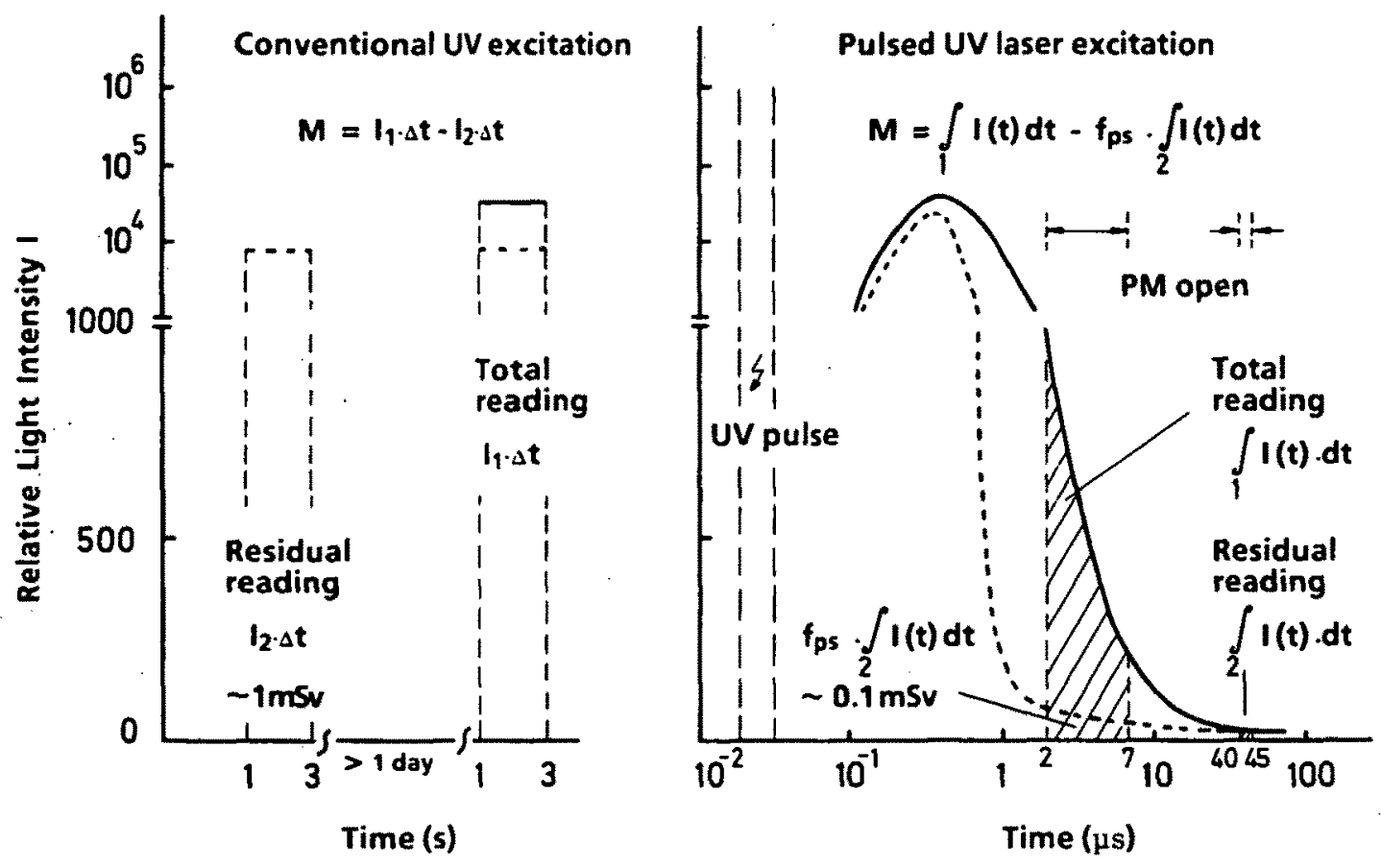

Fig. 2. - Subtraction of the residual dose reading of glass dosemeters using pulsed $U V$ laser excitation vs conventional $U V$ excitation.

Soustraction de la dose individuelle lors de la lecture du verre dosimètre par excitation UV-laser pulsé comparée à l'excitation $U V$ conventionnelle.

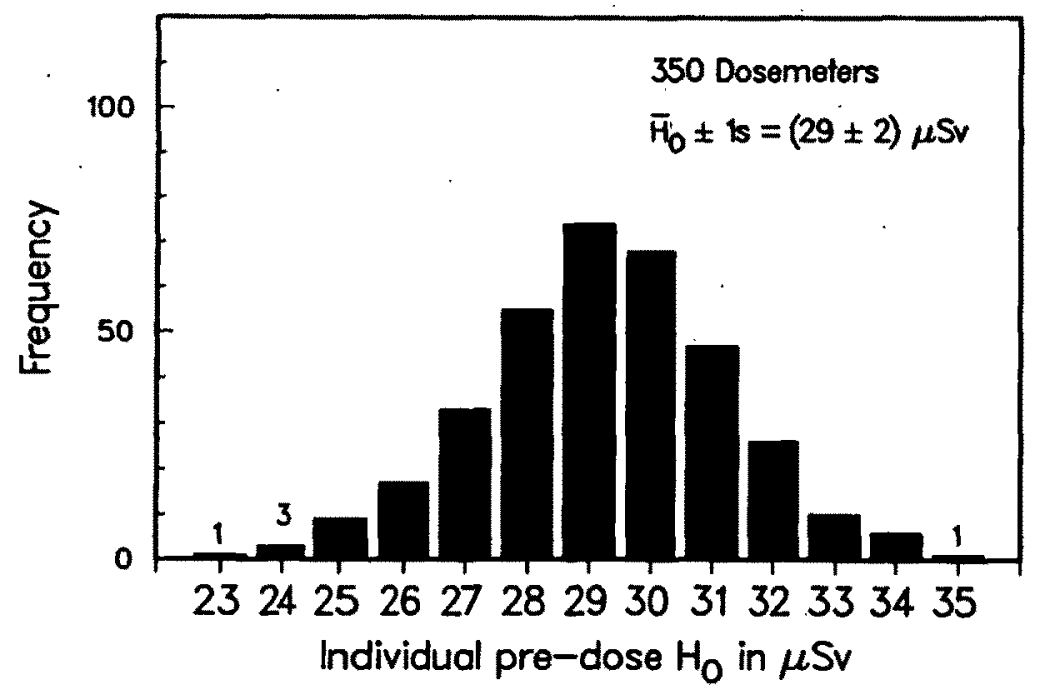

Fig. 3. - Frequency distribution for the pre-dose of annealed glasses.

Distribution de fréquence de la pré-dose des verres trempés. 


\section{Dosimetry system}

The flat glass dosemeter (Fig. 4) consists of a plastic encapsulation $\left(40 \times 30 \times 9 \mathrm{~mm}^{3}\right)$ with energy compensation filters of tin and plastic on both sides and a glass element $\left(16 \times 16 \times 1.5 \mathrm{~mm}^{3}\right)$ fixed in a stainless steel card. The fully automatic readout system Toshiba FGD-10 with a microprocessor controlled evaluation technique (Fig. 5) uses magazines for dosemeters (capsules) as well as for annealed glass cards in order to provide an optional exchange of high-dosed glasses $[4,17]$.

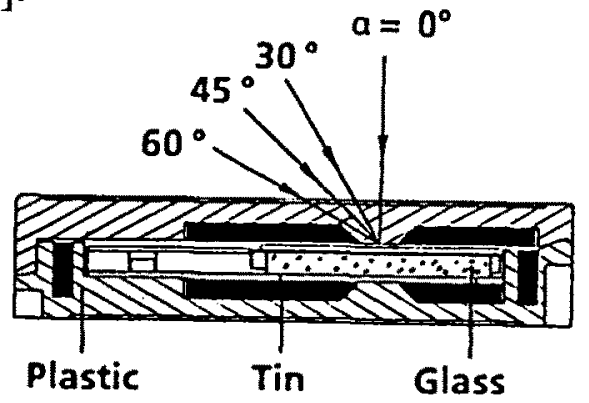

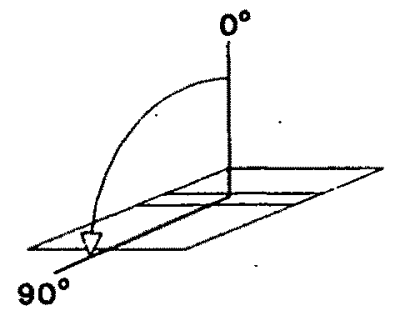

(A)

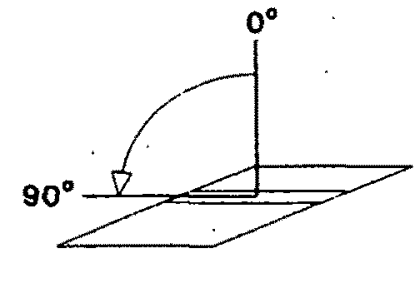

(B)

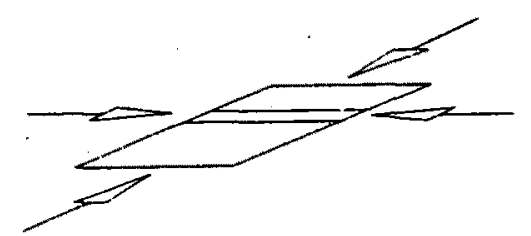

(C)

Fig. 4a. - Cross section and radiation incidence planes $(A, B, C)$ for the flat glass dosemeter. Section efficace et plan d'incidence du rayonnement (ABC) pour le verre dosimètre plan.

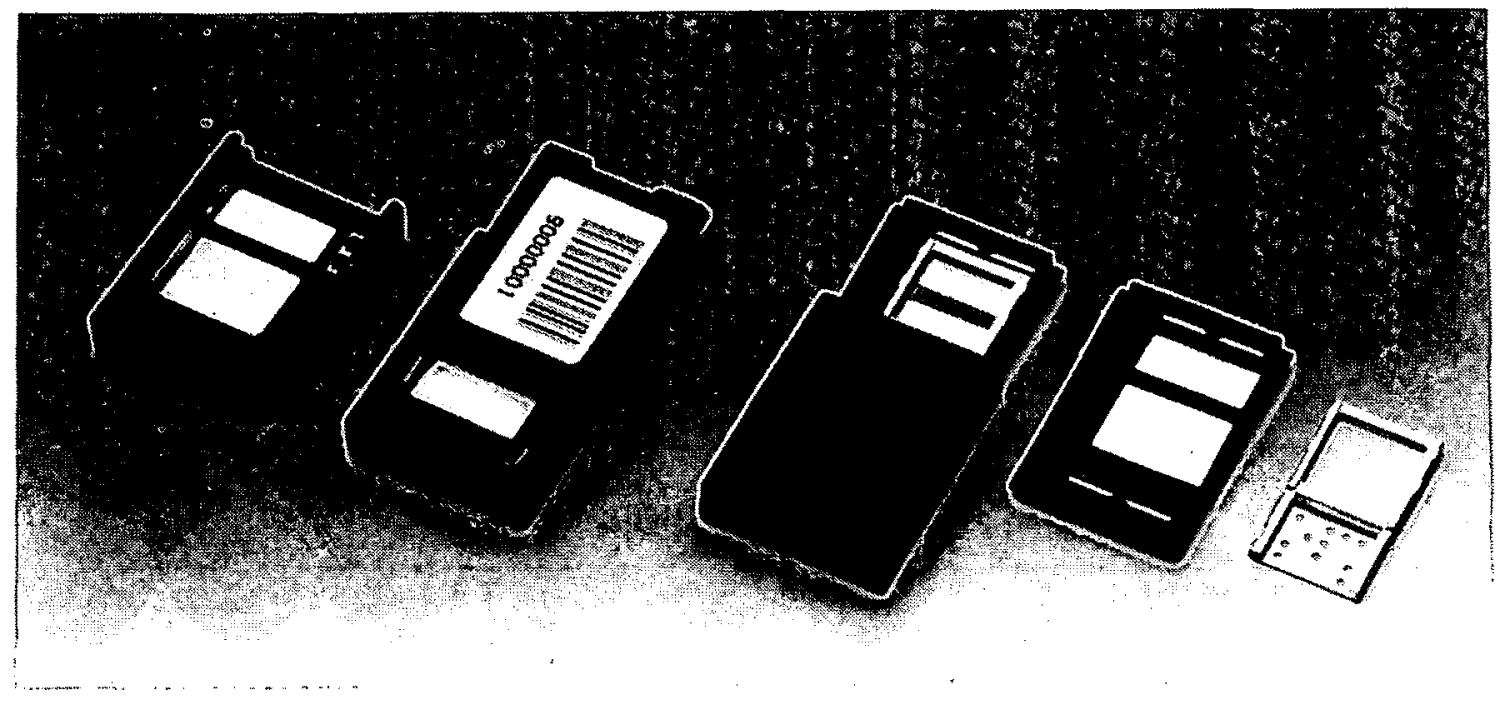

Fig. 4b. - The flat one-element PL phosphate glass dosemeter SC-1.

Le dosimètre plan SC-1 à un élément en verre au phosphate. 
E. PIESCH et al.

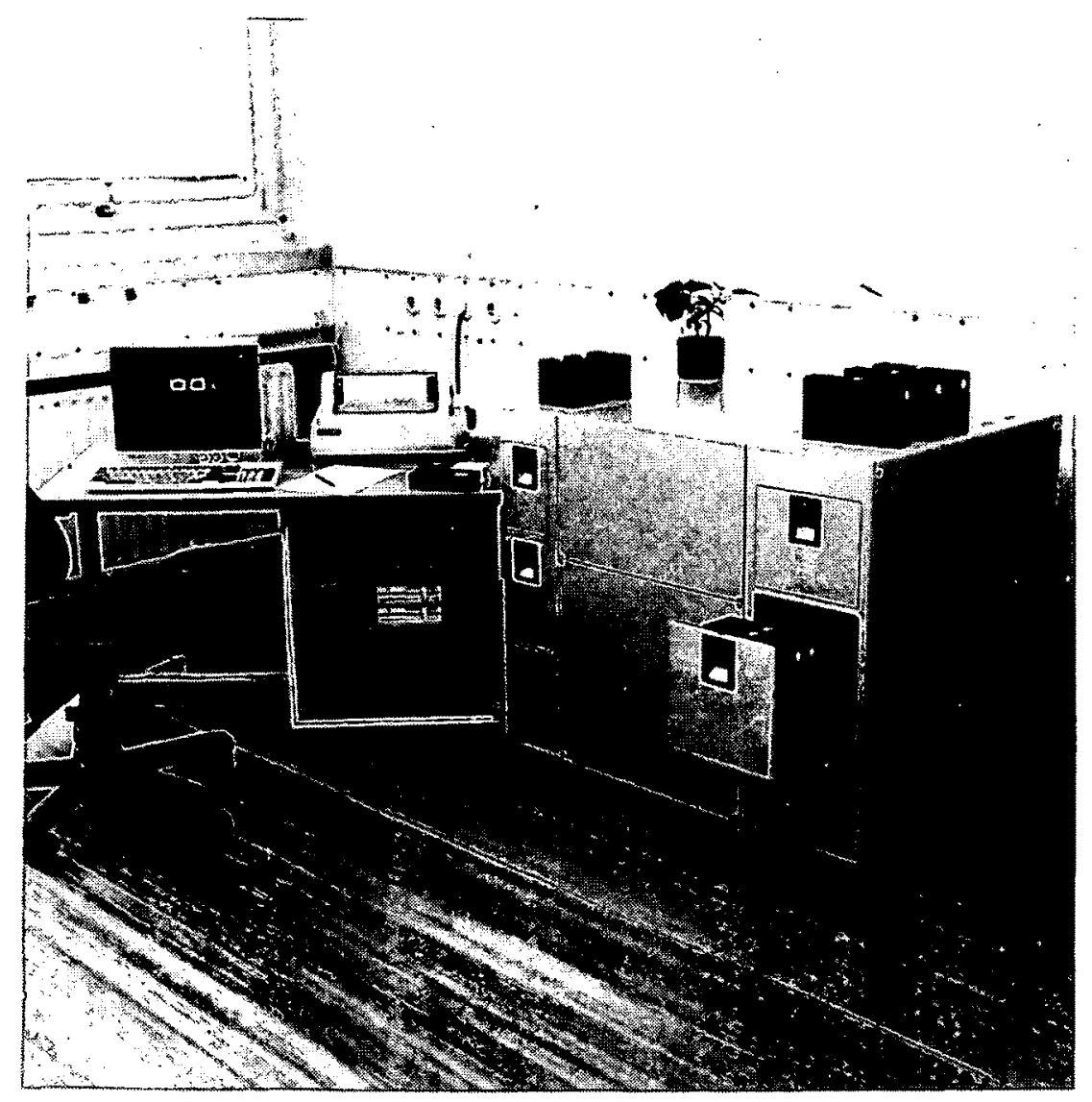

$\boldsymbol{a}$

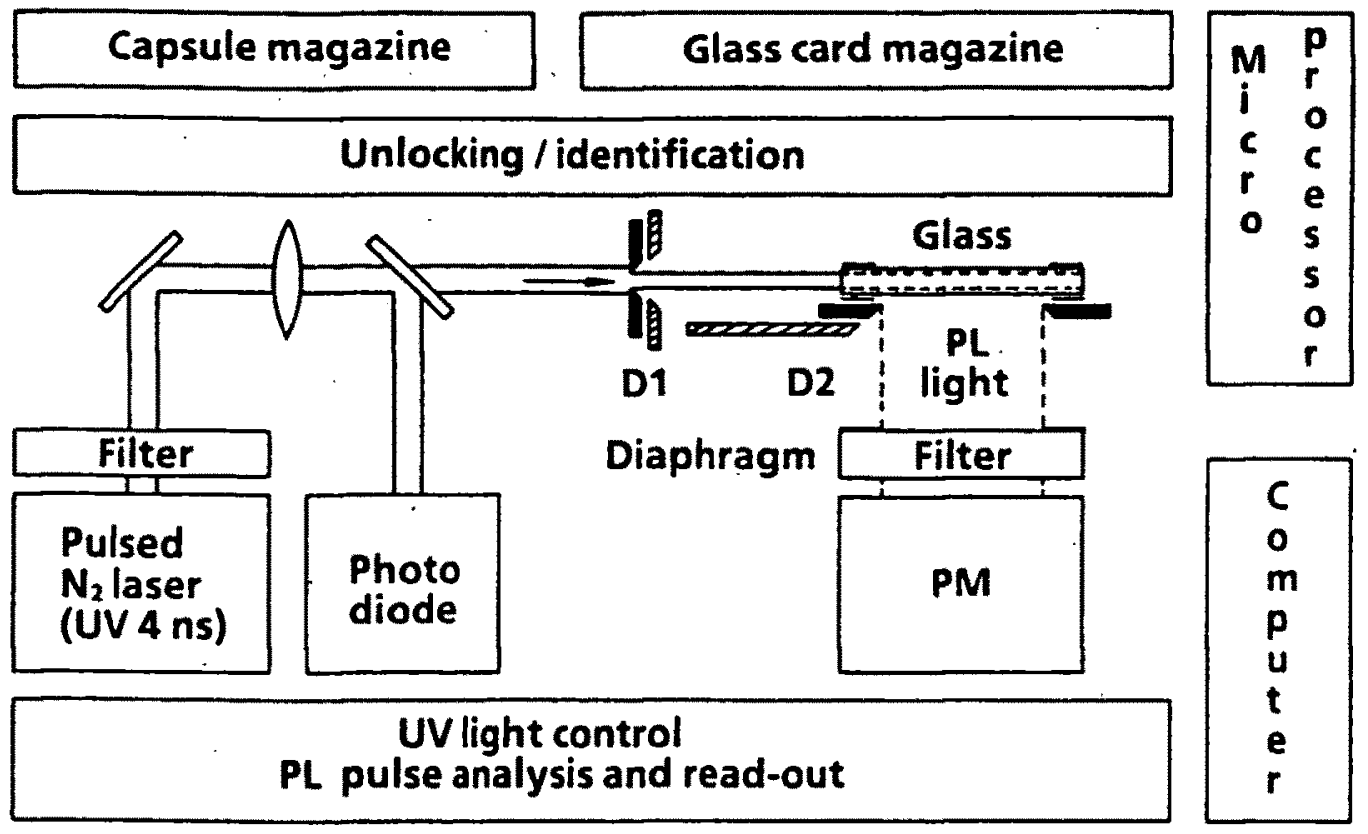

b

Fig. 5. - Toshiba readout system FGD-10 type (a) and automatic readout mechanism in the reader (b).

Le système Toshiba FGD-10 : appareillage (a) et principe de lecture automatique (b). 
Using the threshold mode shown in Figure 6a, automatically movable diaphragms in front of the UV-light source and of the photomultiplier, respectively, allows :

(a) the vertical scanning of the PL intensity in the "near" and "rear" glass parts, where the near part is facing the radiation incidence ; the ratio $M$ (near) $/ M$ (rear) is the parameter to indicate radiation quality in the photon energy range below $30 \mathrm{keV}$ (Fig. 6b);

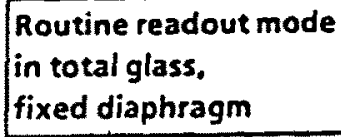

b) in 7 parts of the glass, horizontally movable diaphragm D2
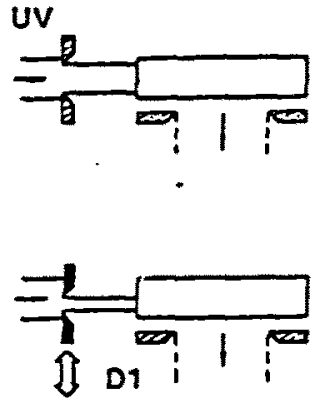

$a$

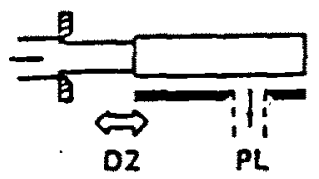

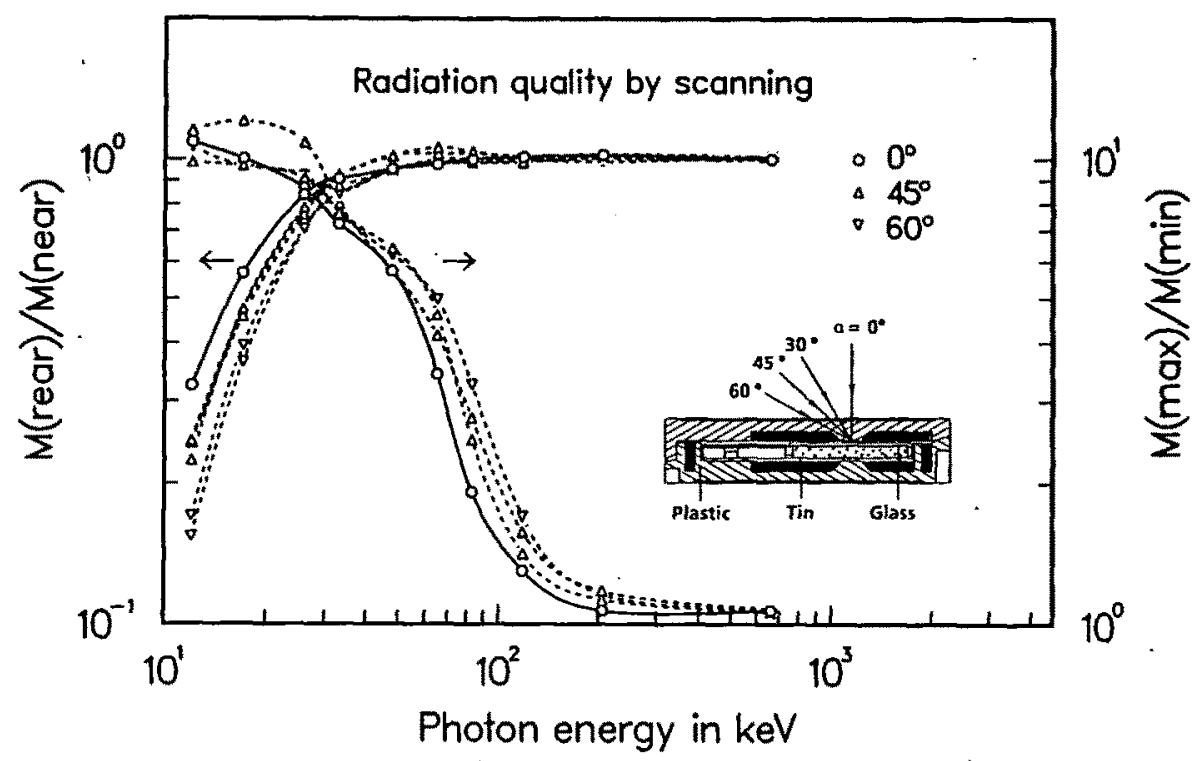

b

Fig. 6. - Readout modes in the automatic readers FGD-10 and FGD-20 (a) and estimation of radiation quality by scanning (b).

Mode de lecture des sytèmes automatiques FGD-10 et FGD-20 (a) et estimation de la qualité du rayonnement par balayage (b). 
(b) the horizontal scanning of the PL intensity in 7 steps along the flat glass surface, which during irradiation is partially shielded by tin and plastic filters ; the ratio of the maximum and minimum values of 7 readouts (Fig. 10) is used to estimate the radiation quality in the photon energy range $30 \mathrm{keV}-150 \mathrm{keV}$ (Fig. 6b).

In general, the fully automatic readout in the FGD-10 includes :

- opening and closing of the dosemeter in the reader,

- continuous reading of up to 500 dosemeters and the data handling for 200000 capsules, the smaller table version FGD-20 is available for the continuous reading of 20 dosemeters,

- exchange of high-dosed with oven-annealed glass cards ( $\$ 5$ ),

- reader calibration by using the same glass for a period of several months $(\S 6)$,

- optional readouts by glass scanning, vertically and horizontally, for indicating radiation quality and angle $(\$ 4.2)$,

- simultaneous indication of different dose quantities ( $\$ 4.1$ ).

\section{Energy and angular dependence}

\subsection{Simultaneous indication of different dose quantities}

The PLD system may simultaneously indicate different dose quantities, such as the new ICRU quantity $H^{\prime}(10)$ [11] or $H_{\mathrm{p}}(10)$ for penetrating radiation in personnel monitoring down to photon energies of about $12 \mathrm{keV}, H_{\mathrm{p}}(0.07)$ for non-penetrating radiation and the exposure free in air, both down to photon energies of about $25 \mathrm{keV}$ (Figs. 7 and 8). Using relevant ${ }^{137} \mathrm{Cs}$ calibration factors $N_{\mathrm{Cs}}(t)$ the readout may be interpreted also in terms of organ doses [16] (Fig. 7, routine readout mode). For $H^{\prime}(10)$ on a sphere phantom, the energy and angular response is shown in Figure 9.

For the PTB type test, glass dosemeters were calibrated free in air in terms of the photon dose equivalent (exposure free in air multiplied by the conversion coefficient $0.01 \mathrm{~Sv} / \mathrm{R}$ ). In the energy range $25 \mathrm{keV}-1.3 \mathrm{MeV}$ and for angles of radiation incidence between $0^{\circ}$ and $60^{\circ}$ from the reference axis, the energy and angular response of the one-element glass dosemeters was $<35 \%$.

In Germany, the choice of the dose quantity is limited up to now to the exposure and a calibration of personal dosemeters "free in air". After the PTB type test, the flat glass dosemeter with the FGD-10 system is now introduced into individual monitoring as an official German dosemeter system for a largescale use for measuring the quantity exposure free in air. When the new ICRU dose quantities are introduced in the near future, then a change of the dosemeter capsule or the readout mode will not be necessary. By changing the calibration factor $N_{\mathrm{Cs}}$ for ${ }^{137} \mathrm{Cs}$ gamma rays, the dose quantity of interest will then be indicated (Fig. 7). 


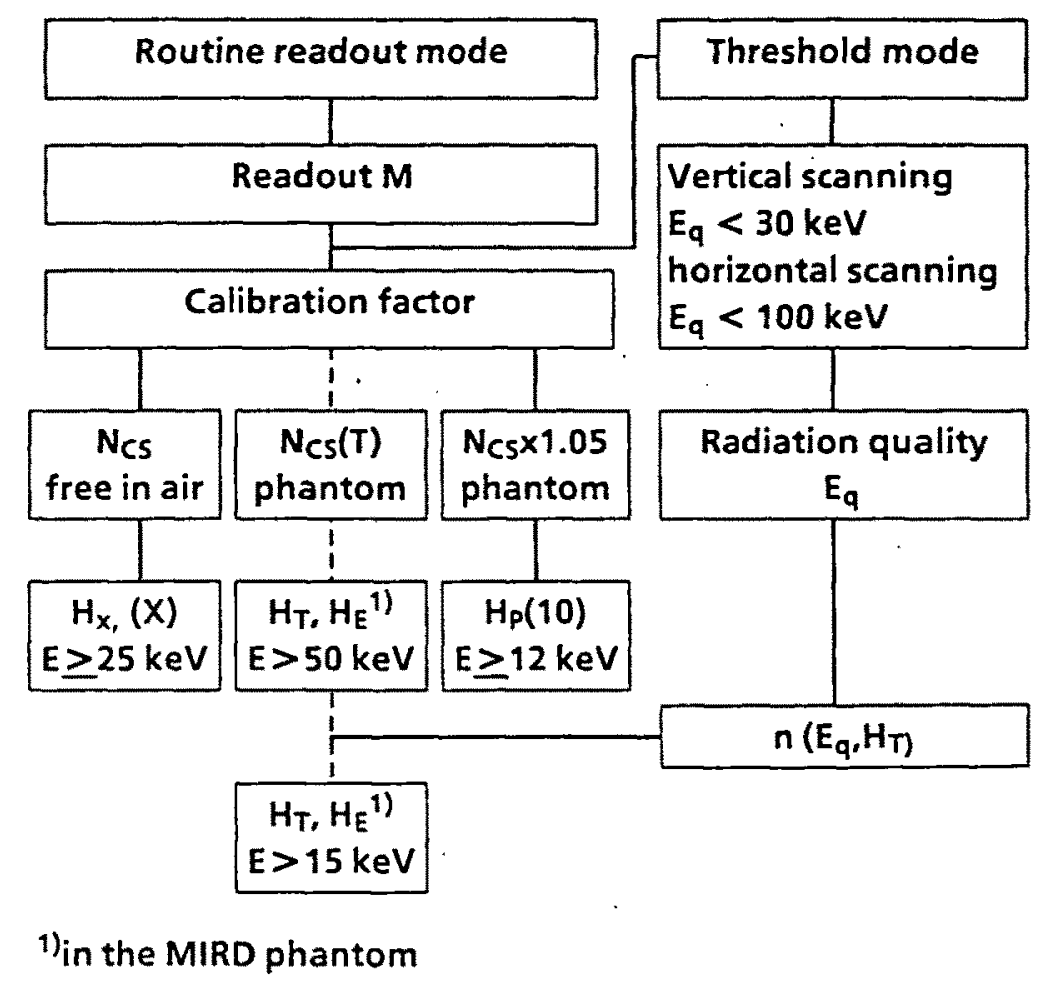

Fig. 7. - Simultaneous indication of different dose quantities in the routine readout mode and estimation of irradiation conditions using the threshold mode in the Toshiba readout systems FGD-10 anf FGD-20.

Indication simultanée des différentes grandeurs dosimétriqus en mode routine et estimation des conditions d'irradiation en mode seuil par les lecteurs FGD-10 et FGD-20.

\subsection{Additional information on radiation quality}

If the readout exceeds a pre-selected threshold, the use of two movable diaphragms, namely one in the UV-beam and the other in front of the photomultiplier, allows automatically for the vertical scanning of the glass in two volume parts and the horizontal scanning in seven volume parts, respectively (Figs. 5 and 6). All results of the routine and the threshold readout are printed out together with the actual range of radiation quality $(<30 \mathrm{keV}, 30-70 \mathrm{keV}, 70$ $150 \mathrm{keV},>150 \mathrm{keV})$. In addition, information about the angle of radiation incidence may be available.

The vertical and horizontal scanning of the glass may provide additional information on radiation quality and the angle of radiation incidence. The capability of the new PLD system was recently demonstrated at the 1990/91 IAEA intercomparison for personnel dosemeters [18]. As an example, Table I compares the IAEA reference data with additional reported $\mathrm{KfK}$ results for the actual photon energy and the angle of radiation incidence, which however have not been used for the dose evaluation. The results of the horizontal scanning are presented in Figure 10 for slab irradiations at photon energies of $57 \mathrm{keV}$ and various angles of radiation incidence. On the basis of these results, 

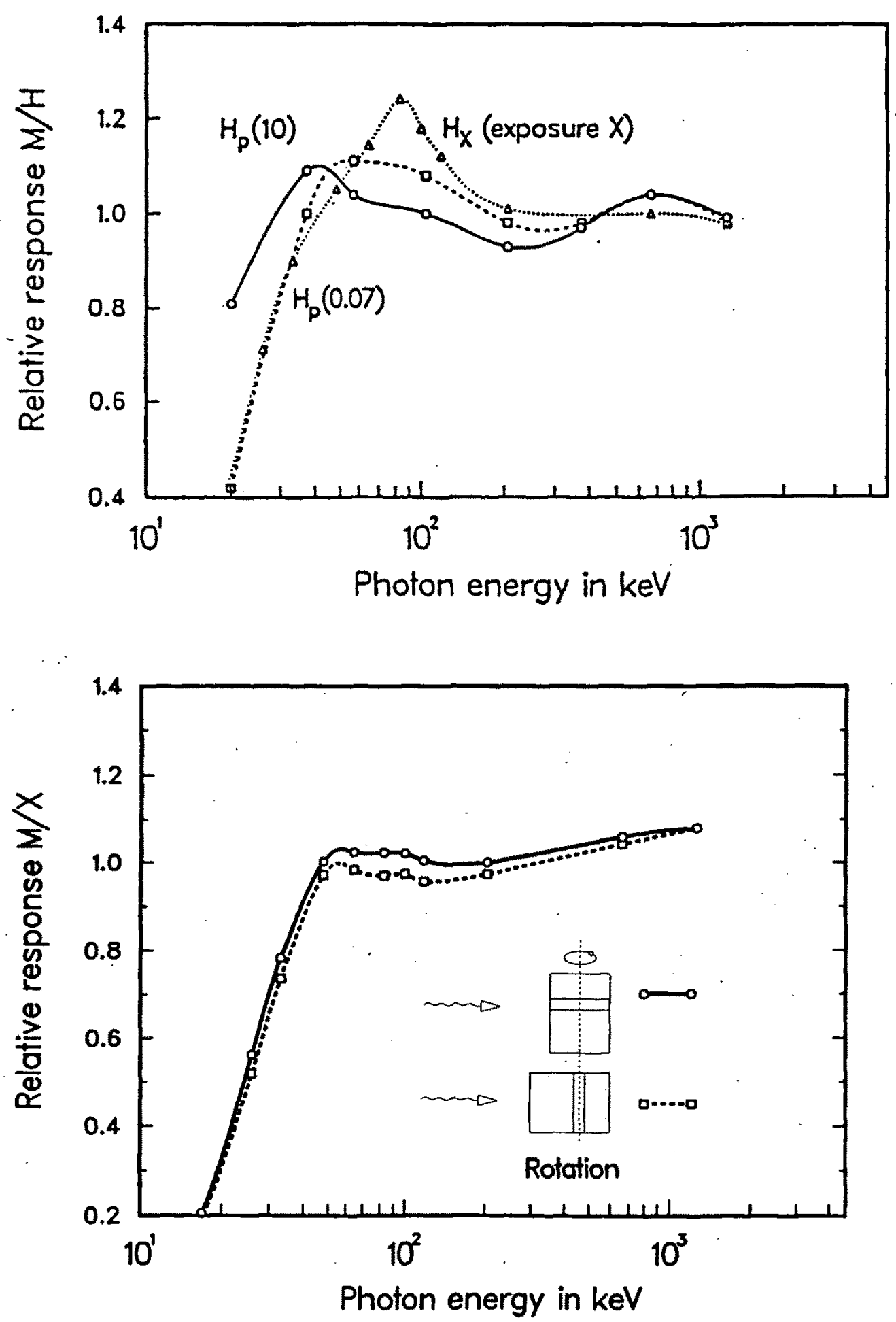

Fig. 8. - Energy response of the flat glass dosimeter: (a) for frontal irradiations on a slab phantom for the measurement of $H_{p}(0.07), H_{p}(10)$ and $H_{x}$ free in air (with $0.01 \mathrm{~Sv} / R)$, (b) for the rotating dosemeter in terms of $H_{x}$ free in air.

Réponse en énergie du verre dosimètre plan : a) irradiation frontale sur un fantome plaque pour la mesure de $H_{p}(0,07), H_{p}(10)$ et $H_{x}$ en espace libre (avec 0,01 $S v / R), b)$ de $H_{x}$ en espace libre avec le dosimètre en rotation. 

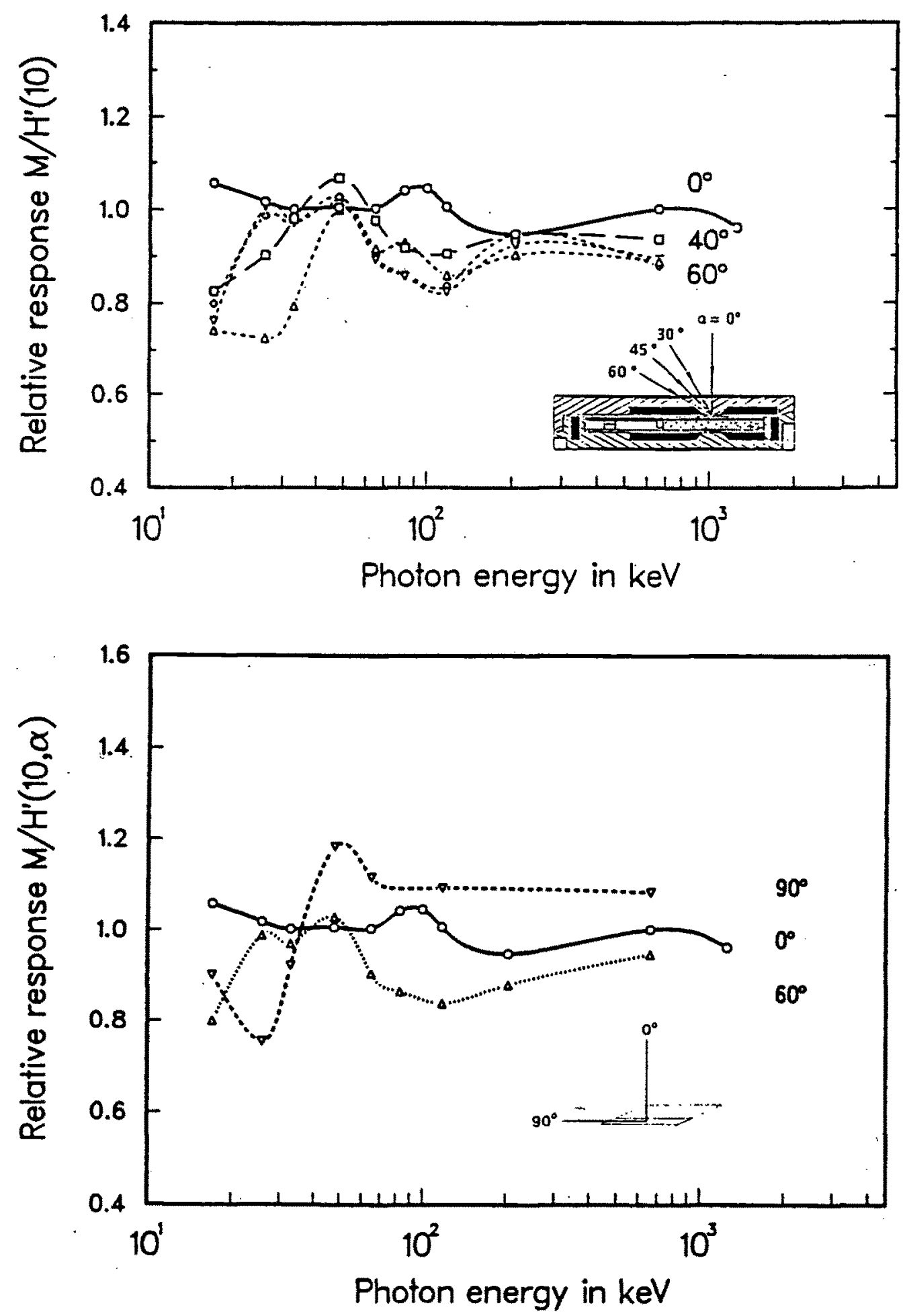

Fig. 9. - Energy and angular response on a sphere phantom for the measurement of $H^{\prime}(10)$ : (a) for irradiation directions from the front half space, (b) under angles of $0,60^{\circ}$, $90^{\circ}$.

Energie et réponse angulaire sur un fantôme sphérique pour la mesure de $\mathrm{H}^{\prime}(10)$ : a) direction des irradiations comprise dans le demi-espace avant ; b) sous des angles de 0,60 et $90^{\circ}$. 
the actual angle of radiation incidence can be estimated qualitatively. The figures allow, for instance, the following interpretation :

- in the horizontal scanning profile, the shift of the maximum readout from the geometric center to a left or right readout position may indicate the angle of radiation incidence as well as the direction from the right or left hand side, respectively (Fig. $10 \mathrm{a}, \mathrm{b}$ ) ; that presentation is particularly possible in the case of irradiations in the plane (A) (Fig. 4a);

- in the case of vertical scanning, the difference in the two relative readouts may indicate irradiation from the near or front side of the dosemeters capsule.

For irradiations at the slab and the Alderson human phantom, on the other hand, the energy and angular response of the flat glass dosemeter including irradiations of the rotating phantom have been found to be consistent within $10 \%[18]$.

For the interpretation of the dosemeter reading in terms of the effective dose equivalent $H_{\mathrm{E}}$ and the relevant organs.(Fig. 11) the energy range may be extended by using the threshold mode (Fig. 7) and the mean photon energy found by scanning as shown in Figure 6. This procedure may be applied also for the indication of exposure in the energy range below $30 \mathrm{keV}$.

\section{Random uncertainty of measurements and dose range}

One of the most essential advantages of the new PLD system is the measurement of low doses in the $10 \mu \mathrm{Sv}$ range. Due to pre-dose suppression, the predose of unirradiated glasses is reduced dramatically to a nominal value of $(30 \pm 1) \mu S v$ (Fig. 3). The consistency of pre-dose values found for about 6000 dosemeters of different production and readout batches, respectively, can be demonstrated by the frequency distribution in Figure 14. The standard deviation of the individual pre-dose scatters for different batches between 1 and $2 \mu \mathrm{Sv}$ only.

The readout program automatically subtracts the individual pre-dose of annealed glasses $H_{0}$ (or the pre-dose reading $H_{1}$ of the last readout) as well as the contribution of the natural background radiation $H_{\text {nat }}$ for the period between the last and the actual readout $M_{2}$ :

$$
H_{2}=N \cdot M_{2}-H_{1}-H_{\text {nat }}
$$

The capability of repeated readouts, unlimited in number, allows the re-use of dosemeters in routine monitoring. Because the random uncertainty increases with the dose accumulated in the previous monitoring period, a glass will be automatically exchanged with an annealed one as soon as the long-term accumulated readout exceeds $3 \mathrm{mSv}$. 
PHOTOLUMINESCENCE DOSIMETRY : THE ALTERNATIVE IN PERSONNEL MONITORING
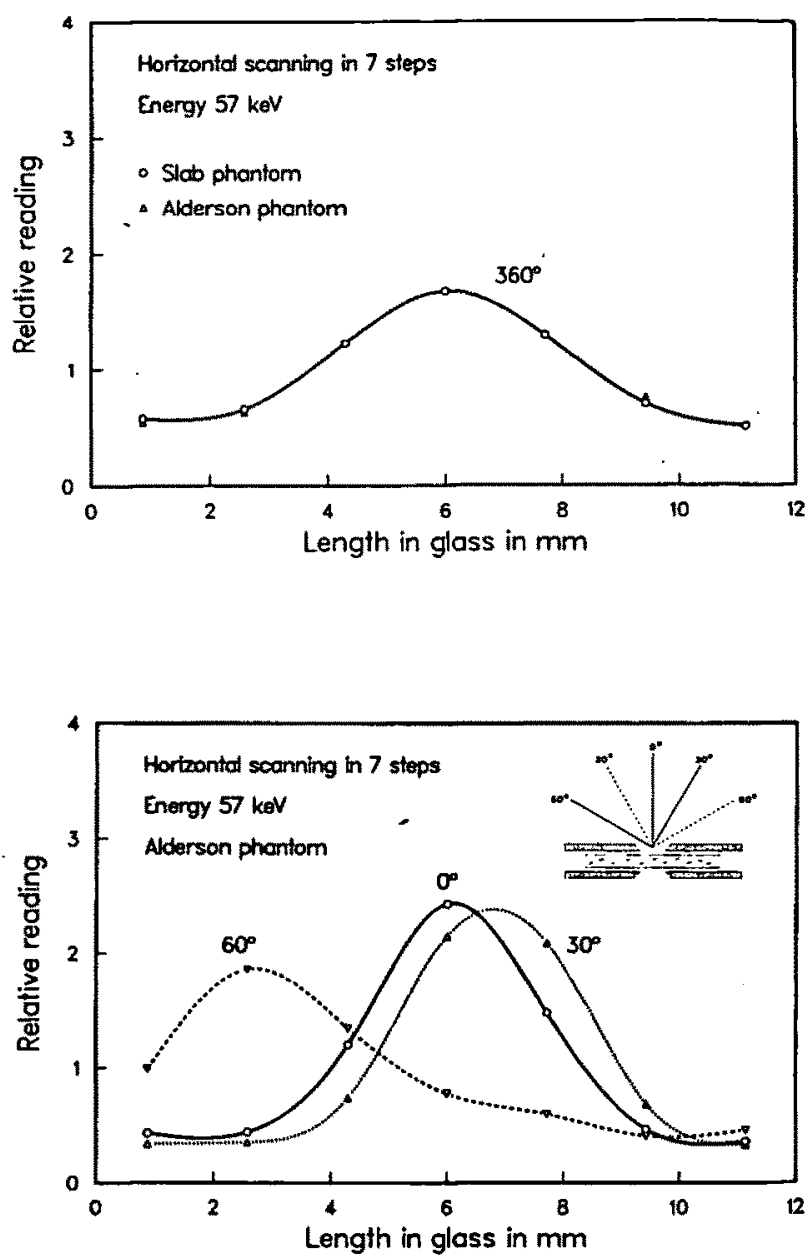

$\boldsymbol{b}$

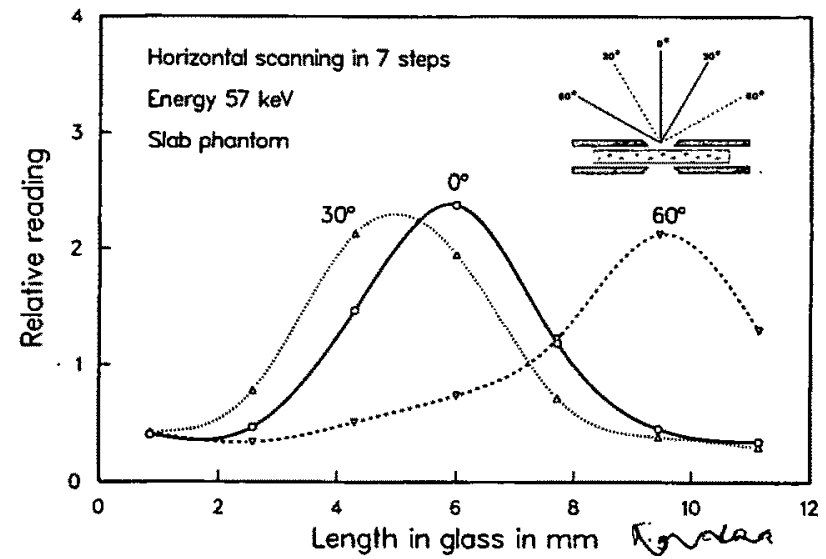

Fig. 10. - Horizontal scanning profiles for different directions of the radiation incidence at $57 \mathrm{keV}$, (a) at the slab phantom, (b) at the Alderson phantom, (c) for the rotating phantom.

Balayage horizontal pour différentes incidences à $57 \mathrm{keV}$ : a) fantôme plaque ; b) fantôme Alderson; c) fantôme en rotation. 
TABLE I

Reported KfK data for radiation quality and angle of radiation incidence and reference data, IAEA intercomparison 1990/91 [18]

Qualité et angle d'incidence du rayonnement, données du KfK et intercomparaison AIEA [18]

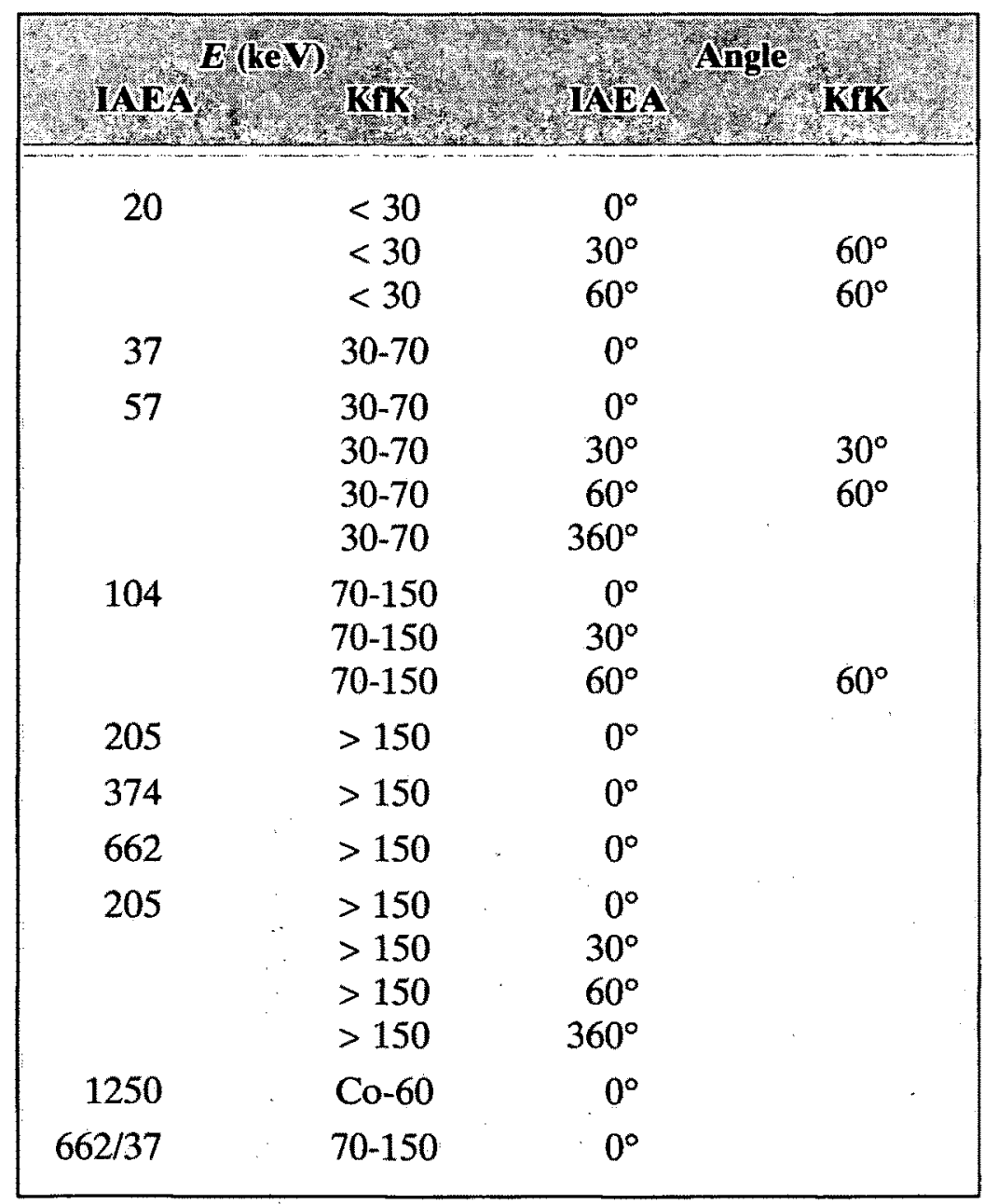

The random uncertainty of dose measurements $v s$ dose has been experimentally investigated for random batches of annealed and pre-exposed dosemeters. Figure 12 shows the coefficient of variation, $v(H)$, estimated for batches of 10 dosemeters as a function of dose. In routine monitoring, the actual dose contribution is given by the difference of two consecutive readouts at the beginning and the end of the monitoring period. Using random batches of annealed glasses with a pre-dose of $0.03 \mathrm{mSv}$ or batches which have previously accumulated a total dose of $3 \mathrm{mSv}$, the dose equivalent of $0.1 \mathrm{mSv}$ can be measured with a coefficient of variation of $3 \%$ and about $25 \%$, respectively. Above $0.6 \mathrm{mSv}$, the coefficient of variation for a random batch of annealed dosemeters is about $1 \%$ due to the uncorrected scatter in the individual detector response, but for the same glass detector in routine monitoring about $0.5 \%$. 


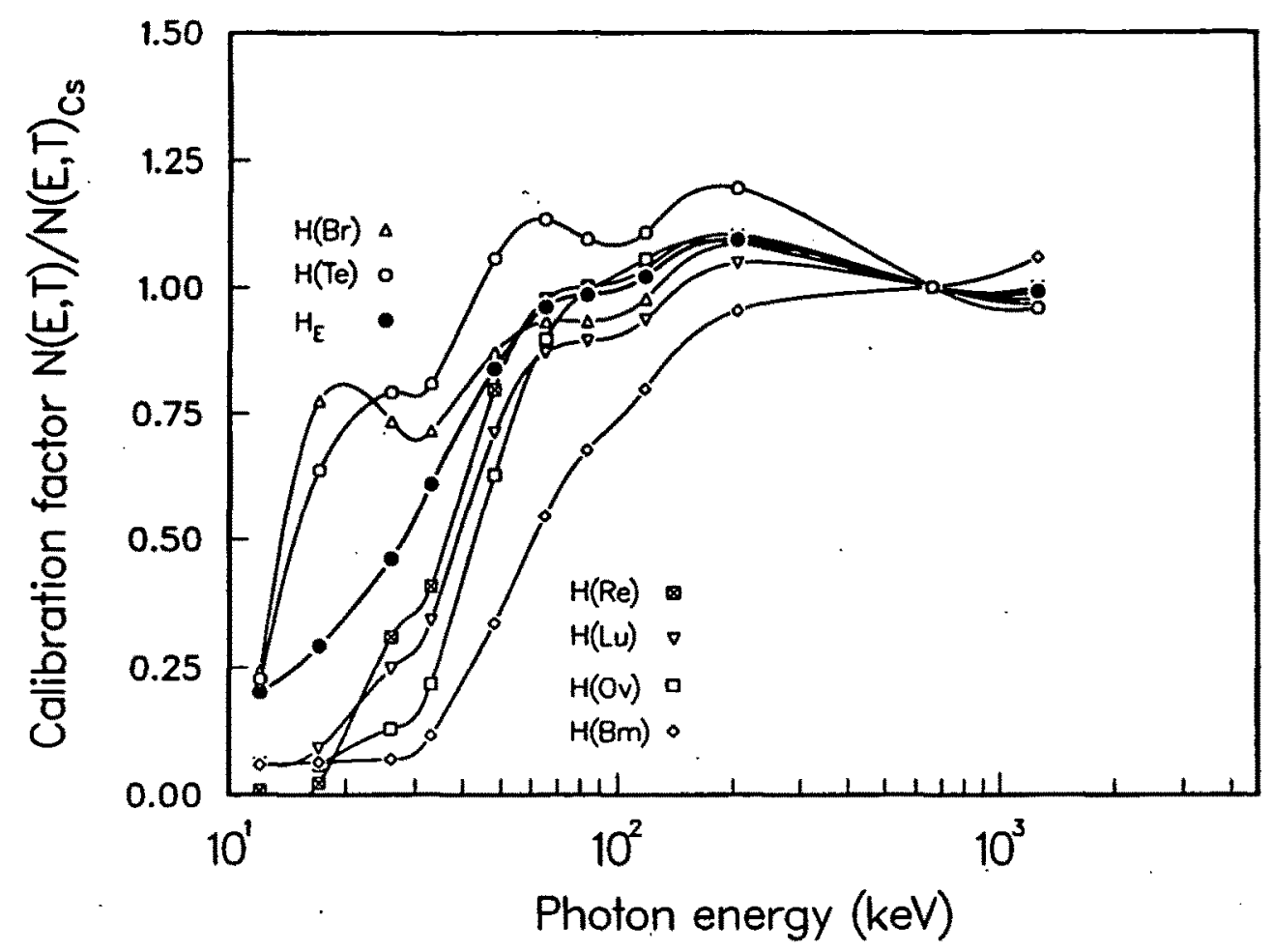

Fig. 11. - Relative calibration factors for the flat glass dosemeter for reading interpretation in terms of organ doses $\mathrm{H}_{T}$ and effective dose equivalent $\mathrm{H}_{E}$.

Facteurs d'étalonnage relatifs pour le verre dosimètre plan pour l'interprétation de la lecture en terme de dose aux organes $\mathrm{H}_{T}$ et d'équivalent de dose efficace $\mathrm{H}_{E}$.

According to the PTB type test criteria [1], the dose range is $0.1 \mathrm{mSv}-8 \mathrm{~Sv}$ for personnel dosemeters and $0.03 \mathrm{mSv}-8 \mathrm{~Sv}$ for area dosemeters, respectively. On the basis of the expected value of the empirical standard deviation $s_{0}$, the lower limit of detection given by $H(L L D)=\left(t_{1-\alpha}+t_{1-\beta}\right) \cdot s_{0}$ with $t_{1-\alpha}=t_{1-\beta}=$ 1.65 for a confidence level of $95 \%$ was found to be $0.1 \mathrm{mSv}$ for the PLD system, if the total accumulated dose before use was smaller than $3 \mathrm{mSv}$, and about $0.01 \mathrm{mSv}$ for a PLD system requiring annealing of the glass before use.

\section{Accuracy and long-term stability of dose measurement}

Above all, the accuracy of measurement for long-term monitoring periods is one of the essential advantages of the PLD system. It is mainly the simplicity of the readout and the calibration technique that result in long-term stability of the PLD system. For the daily calibration of the readout system, the same glass may be used over periods of about 6 months. In addition, any changes in the UV-laser intensity are automatically corrected and checked by an internal calibration glass. 


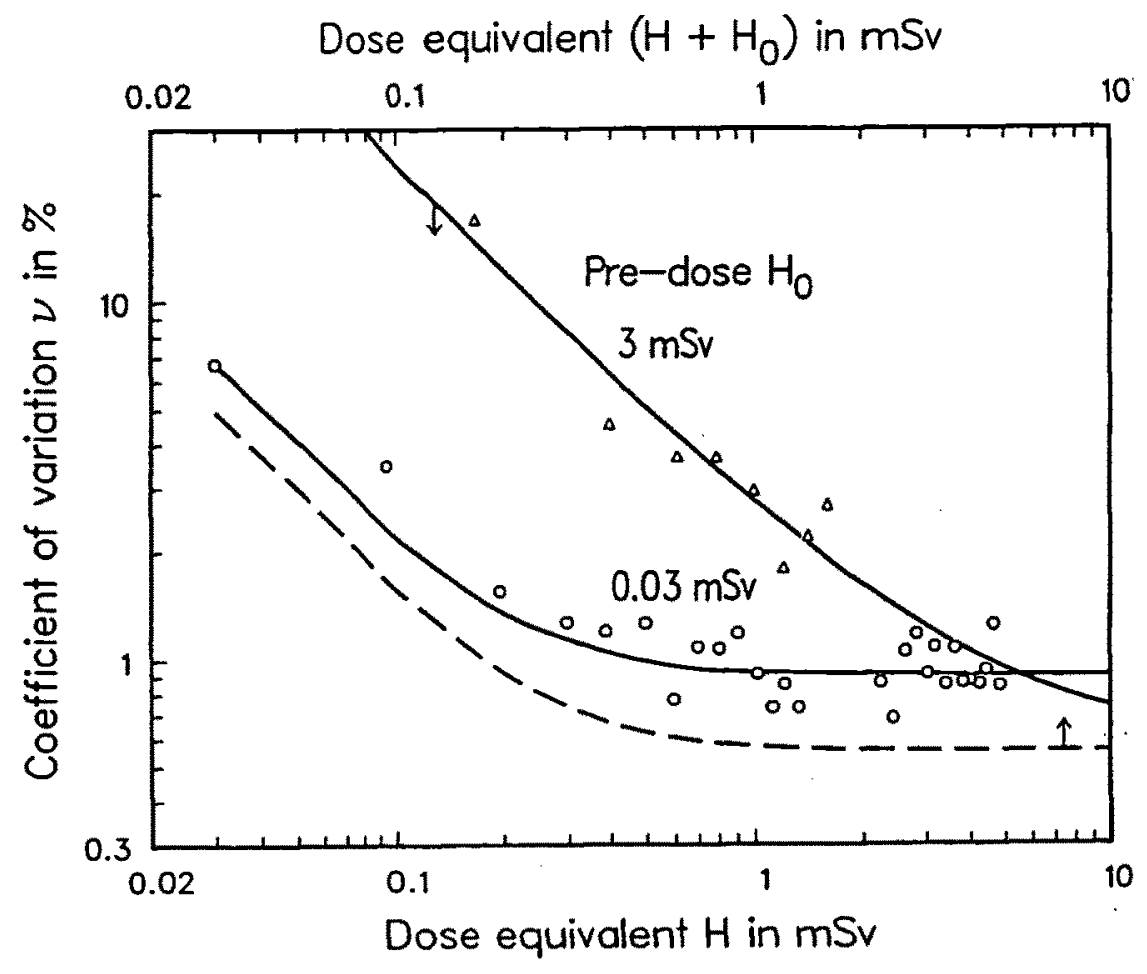

Fig. 12. - Coefficient of variation for photon dose measurements using batches of annealed glasses (pre-dose $0.03 \mathrm{mSv}$ ) and glasses with an accumulated dose of $3 \mathrm{mSv}$. The dashed curve represents the results of repeated measurements using annealed glasses.

Coefficient de variation pour la mesure des doses de photons avec des lots de verre trempé (pré-dose : $0,03 \mathrm{mSv}$ ) ou avec une dose cumulée de $3 \mathrm{mSv}$; - - - mesures répétées avec des verres trempés.

On the other hand, ambient parameters which may affect the precision of measurement within routine monitoring are : the build-up of the PL intensity immediately after exposure, humidity, temperature during exposure, storage (fading) and readout as well as quenching due to UV-light excitation. Table II shows that only build-up and temperature effect during exposure may contribute to the uncertainty of measurement. These parameters are controlled by a proper readout technique. The glass detector is insensitive to ambient temperature and humidity influences as well as to dirtiness of the glass surface. As a result of the latter characteristic, glass cleaning is no longer necessary.

Batches of glass dosemeters have been consecutively irradiated and measured over periods of more than 3 months using low exposures in steps of 50 and $100 \mu \mathrm{Sv}$, respectively. For consecutive measurements of the same batch, the ratio of the actual dose and the accumulated reference dose has been found to be within $\pm 1.3 \%$ (Fig. 13). This long-term stability of the system includes errors of consecutive irradiations, repeated reader calibrations as well as the time dependent build-up of the PL intensity. 
TABLE II

Ambient parameters affecting measurement accuracy Paramètres d'ambiance affectant la précision des mesures

\begin{tabular}{|lcl|}
\hline \multicolumn{1}{|c|}{ Parameter } & Change in read-out & Effect \\
\hline $\begin{array}{l}\text { Build-up of } \mathrm{PL} \text { intensity } \\
\text { at } 20^{\circ} \mathrm{C} \text { between } 7 \mathrm{~d} / 40 \mathrm{~d} \\
\text { after irradiation }\end{array}$ & $+2 \%$ & $\begin{array}{l}\text { Negligible if thermal treatment } \\
\text { before readout }\end{array}$ \\
$\begin{array}{l}\text { Humidity } \\
90 \% \mathrm{RH} / 80^{\circ} \mathrm{C} / 7 \text { days }\end{array}$ & no effect & Glass washing not necessary \\
$\begin{array}{l}\text { Temperature } T \text { during irradiation } \\
\text { storage at }\end{array}$ & $<0.1 \% /{ }^{\circ} \mathrm{C}$ & $<2 \%$ up to $40^{\circ} \mathrm{C}$ \\
$\begin{array}{l}6{ }^{\circ} \mathrm{C} / 100 \text { days } \\
30^{\circ} \mathrm{C} / 8 \text { years } \\
\text { readout }\end{array}$ & $<0.5 \%$ & $\begin{array}{l}\text { Fading correction } \\
\text { negligible }\end{array}$ \\
$\begin{array}{l}\Delta T \text { between calibration glass } \\
\text { and routine glasses }\end{array}$ & $-2 \%$ & $\begin{array}{l}\text { Negligible because same } T \\
\text { during readout }\end{array}$ \\
$\begin{array}{l}\text { UV quenching and recovery } \\
\text { of readout after } 3,500 \text { readouts }\end{array}$ & $-1 \%$ & Negligible \\
\hline
\end{tabular}

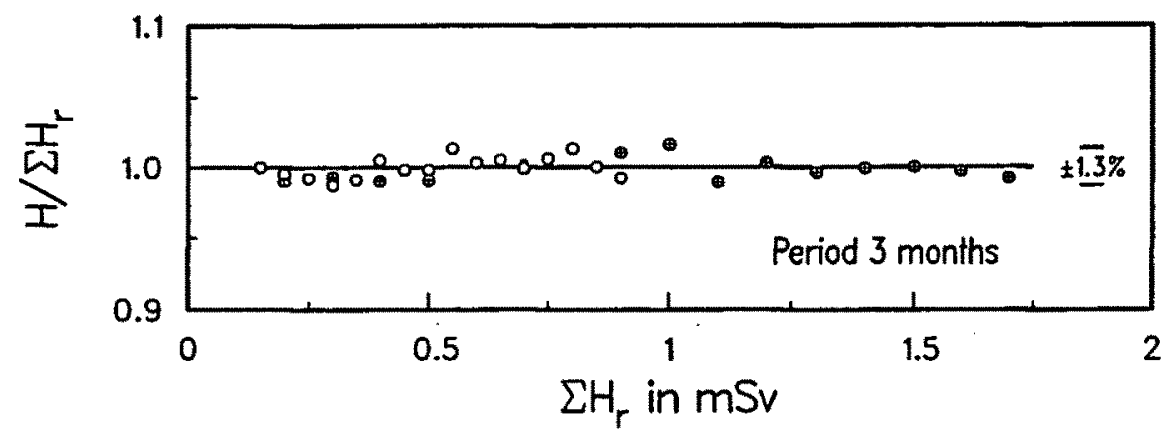

Fig. 13. - Mean values of the relative accumulated dose readings after consecutive irradiations of glass dosemeters.

Moyenne des doses relatives cumulées après irradiations successives des verres dosimètres.

\section{Specific advantages of PLD-systems in comparison to other dosemeter types}

\subsection{Readout technique}

The flat glass dosemeter is a one-element dosemeter, i.e. the readout gives directly the measured dose equivalent $H_{\mathrm{p}}(10)$ in the energy range from $12 \mathrm{keV}$ to $1.3 \mathrm{MeV}$. Similar to electronic dosemeters, the readout of the glass may be repeated, unlike the irreversible changes of the accumulated dose information due to the development of the film or the heating-up procedure of TL detec- 
tors. One-element electronic dosemeters with GM-counters have a restricted energy range above $50 \mathrm{keV}$. New types of electronic dosemeters with at least two diode detectors behind different shields measure $H_{\mathrm{p}}(10)$ in the energy range above $25 \mathrm{keV}$.

For the reduction of energy dependence of $H_{\mathrm{p}}(10)$, some TLD systems as well as film dosemeters make use of 4 or more detectors which may vary in TL materials and in front and backside shielding, respectively, and $H_{\mathrm{p}}(10)$ is estimated by a linear combination of the readings.

For the calibration of the glass dosimetry system, the same calibration glass is used over a period of 6 months. TLD systems, however, require for the daily reader calibration about 10 irradiated and 10 unirradiated detectors. Because of non-linearity, film dosimetry systems need the estimation of the calibration curve over the whole dose range of interest.

In comparison to a one-element dosemeter, the uncertainty of a multi-element dosemeter is generally expected to be higher due to the evaluation algorithm especially from the shielding effect to the detectors for a non-frontal irradiation.

\subsection{Basic dosimetric properties}

Glass dosemeters are also comparable with electronic dosemeters with respect to the simplicity of readout, the continuous dose accumulation, the capacity of repeated readouts within a long-term dose accumulation period and the low coefficient of variation in the $10 \mu \mathrm{Sv}$ dose range.

The PLD system is now comparable with TLD systems in the fully automatic readout, but has been found to be superior in their dosimetric properties such as simplicity of readout and calibration, good batch uniformity in response and background reading, insensitivity against ambient temperature and humidity effects.

In comparison with TLD systems, the PLD system shows a good uniformity in the detector response with a maximum scatter of $<0.5 \%$ and in the pre-dose reading of annealed glasses (Fig. 14) which is about one magnitude of order lower than that for LiF:Mg,Ti. During a readout, on the other hand, the individual pre-dose is subtracted automatically. The effect of typical surface contaminations on TLD 700 may change the pre-dose reading significantly. The undetected chemoluminescence of the contaminants may stimulate a radiationinduced readout above all at low exposures. Similar effects of photoluminescence on the glass surface have not been found in PL dosimetry, if pulsed UVlaser excitation is applied.

The random uncertainty of measurements and thus $H_{\min }$ is given by the coefficient of variation which is presented in Figure 15 as a function of dose for an automatic readout in the Alnor Dosacus reader for TLD 700 and the Toshiba FGD-10 reader for the glass dosemeter. In personnel monitoring, 
glasses are annealed in an oven only after a dose accumulation up to $3 \mathrm{mSv}$. The random uncertainty of glass dosemeters is comparable with that of TLD 700 in the case of oven annealing, for higher doses above $1 \mathrm{mSv}$, however, lower by more than a factor of 2 .
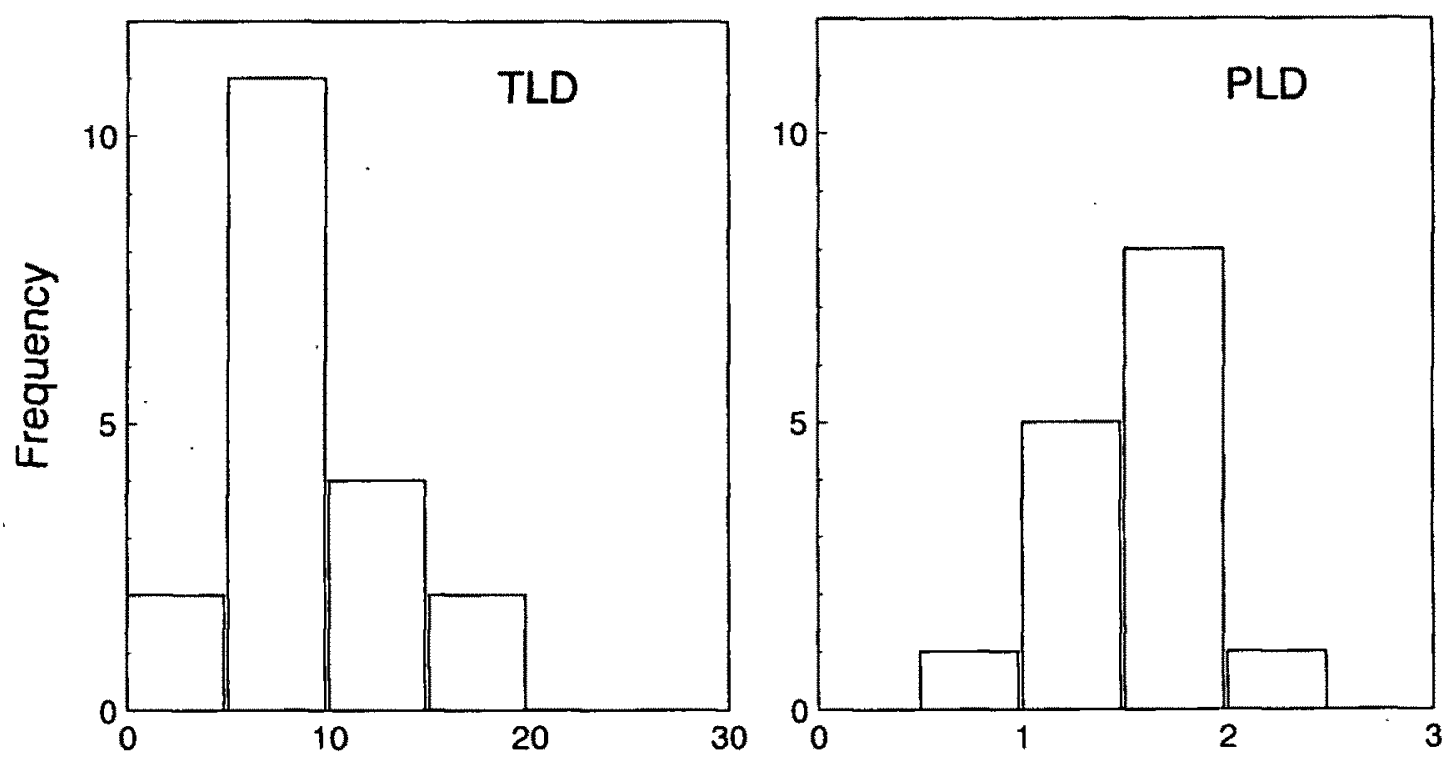

Standard deviation of pre-dose in $\mu \mathrm{S} v$

Fig. 14. - Frequency distribution for the standard deviation of the pre-dose for different batches of TL and PL detectors measured with fully automatic dosimetry system. Distribution de fréquence de l'écart-type de la pré-dose pour différents lots de détecteurs TL et PL mesurée avec le système automatique.

\subsection{Ambient effects}

Mainly lack in thermal stability and sensitivity against environmental effects limits the application of TLD systems in routine monitoring. In comparison to other dosemeters such as TL and film dosemeters, glass dosemeters are most stable against environmental effects. Within routine monitoring, the accuracy of dose measurement is essentially affected by the temperature used for the annealing and the temperature during the irradiation, the storage as well as the readout. It is well-known that film dosemeters show an extreme dependence on ambient temperature, namely an increase of the latent image (dose reading) of unexposed films during transportation and storage at higher temperatures as well as a decrease of the latent reading of irradiated films (fading). For elevated ambient temperatures up to $40^{\circ} \mathrm{C}$ within individual monitoring the fading of TLD 700 chips, for instance, was found to be up to $15 \%$ and for $\mathrm{Li}_{2} \mathrm{~B}_{4} \mathrm{O}_{7}$ : $\mathrm{Mn}, \mathrm{Si}$ up to $30 \%$ [5] taking into account a short-term irradiation between 7 and 40 days before the readout and an optimized post-irradiation treatment (Fig. 16). For the PLD system, we expect an increase in the readout in glasses of about $2 \%$ only during irradiation. In the case of environmental monitoring, 
the ambient temperature may exceed $50^{\circ} \mathrm{C}$. In comparison with TLD systems, the temperature effect of glass dosemeters is expected to be one order of magnitude lower also at elevated temperatures. Earlier experiments indicated a long-term fading of $-2 \%$ after 8 years of storage at $30^{\circ} \mathrm{C}[7]$.

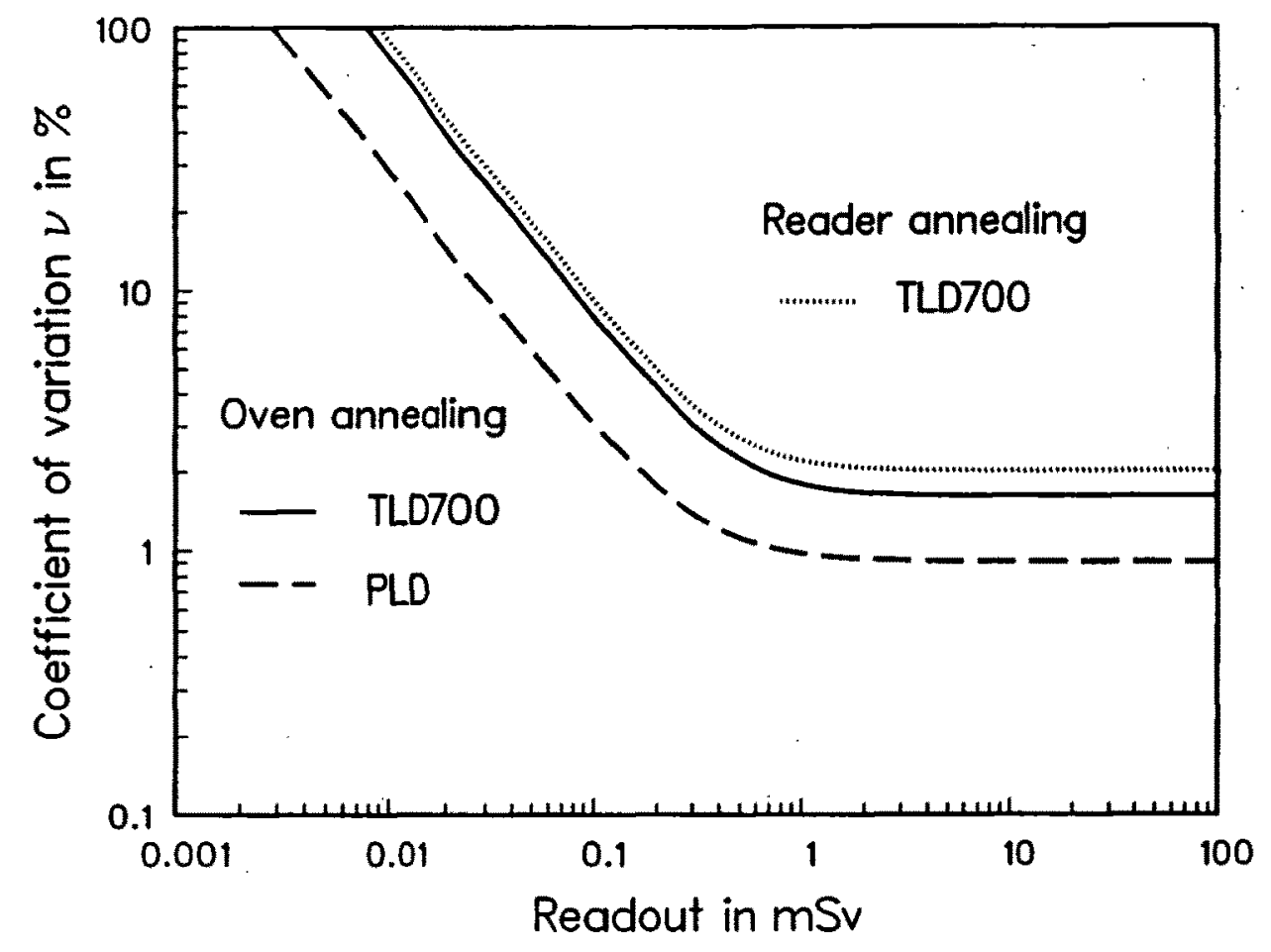

Fig. 15. - Coefficient of variation for the routine measurement of photon doses using oven annealed and reader annealed TLD 700 after readout in an. Alnor reader, and annealed glasses for readout in the FGD-10 reader.

Coefficient de variation pour la mesure en routine des doses de photons d'une part par TLD 700 trempés au four et au lecteur, après lecture dans un lecteur Alnor, et d'autre part par verre trempé avant lecture dans le FGD-10.

\subsection{Quality assurance}

The energy and angular dependence of a dosemeter system is the most important parameter which may affect the overall uncertainty of measurement in the dose range above $1 \mathrm{mSv}$.

The experiments of the quality assurance test and the pattern approval at the PTB have shown that the long-term stability and reproducibility of measurement of the flat glass dosemeter is about $1 \%$ ( $2 s$-value). In radiation fields, such as X-ray beams in medical diagnosis, the glass dosemeter may serve as a suitable reference dosemeter for quality control allowing high accuracy of dose estimation of radiation quality. 


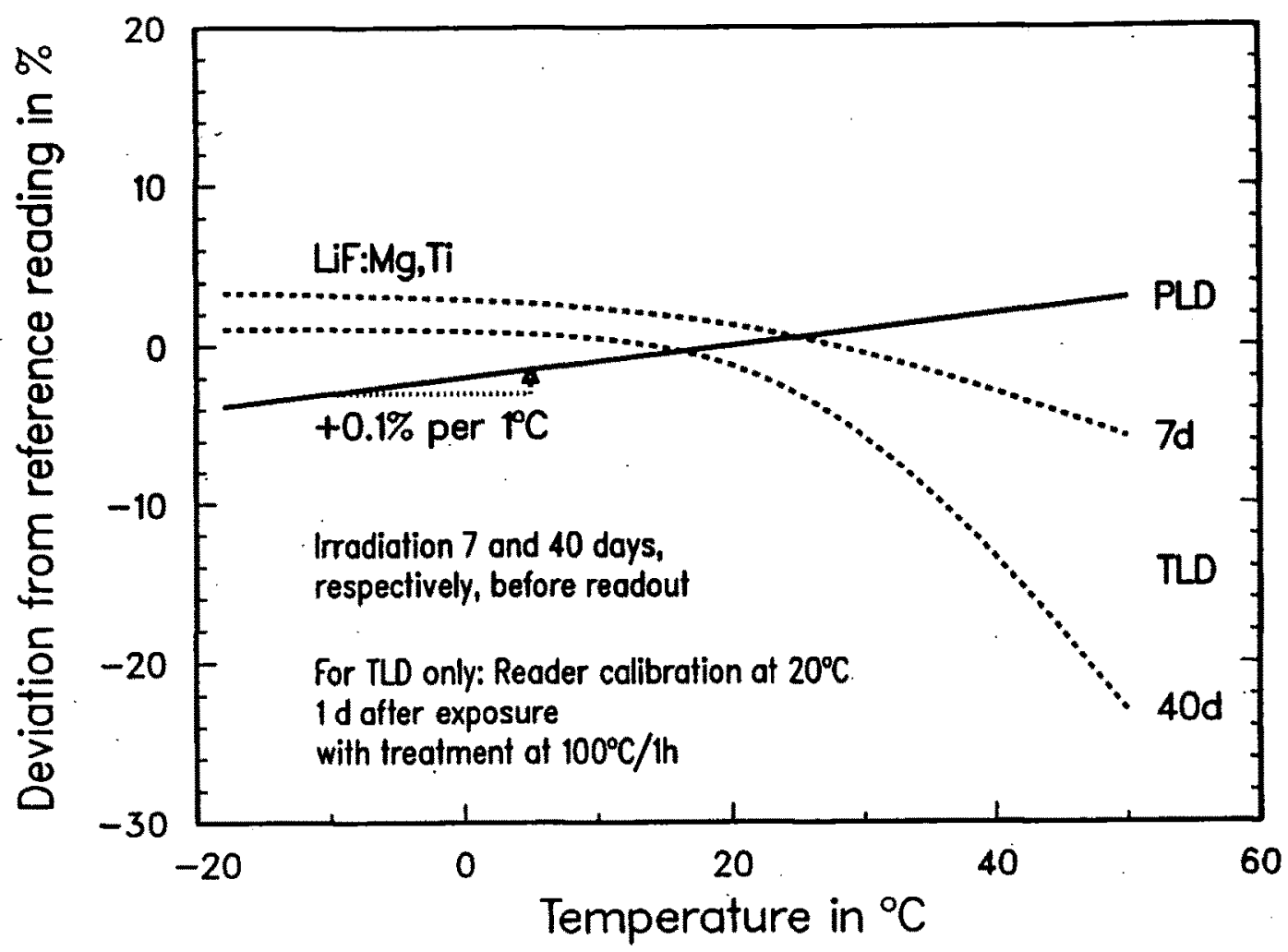

Fig. 16. - Ambient temperature effects on PLD and on LiF-TLD systems vs ambient temperature within routine monitoring on a monthly basis.

Effet de la température ambiante sur les dispositifs PLD et LiF-TLD en fonction de la température au cours d'une surveillance de routine à fréquence mensuelle.

At the 1990/91 IAEA intercomparison [3], optimization of the photon energy response with respect to $H_{\mathrm{p}}(10)$ was investigated for various dosimetry systems. Figure 17 compares the results of the participants which were reported for the energy dependence of their dosemeter systems in terms of the coefficient of variation, $v\left(H-H_{r}\right)$, for the deviation of the reported dose equivalent $H$ from the reference dose equivalent $H_{\mathrm{r}}$ for frontal irradiation in the photon energy range of interest. The one-element glass dosemeter with a $v$-value of $8 \%$ has been found to be comparable with the best TLD systems which, however, use 4 detectors of various $\mathrm{TL}$ materials $\left(\mathrm{Li}_{2} \mathrm{~B}_{4} \mathrm{O}_{7}\right.$ and $\left.\mathrm{CaSO}_{4}\right)$ and shieldings, respectively on the front and rear side of the dosemeter (unsymmetric albedo type dosemeter). Taking into account the angular response up to angles of $60^{\circ}$ the flat glass dosemeter expects a maximum deviation up to $30 \%$.

\section{Pattern approval results}

After long-term development and tests, Toshiba Glass as the manufacturer of the system received the PTB pattern approval for the PLD system both as individual and area dosemeter [1]. The first PTB type test of a commercially 


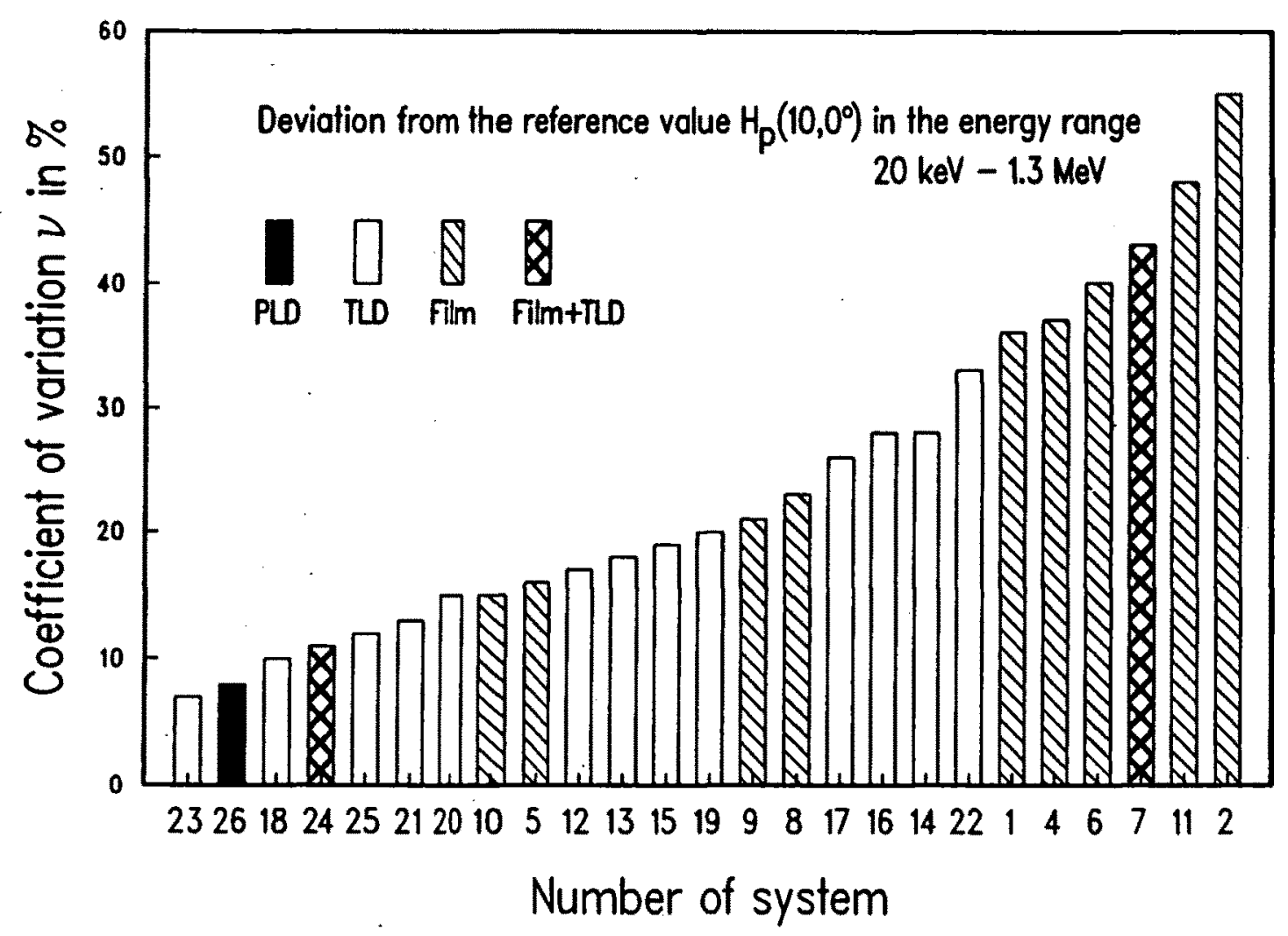

Fig. 17. - Frequency distribution for the variation coefficients of dose measurements for the individual dosemeter systems participating in the 1990/91 IAEA intercomparison [18].

Distribution de fréquence du coefficient de variation des mesures lors de l'intercomparaison de l'AIEA [18].

available dosemeter system confirmed the excellent dosimetric properties. The type test of dosemeter systems for individual monitoring is mandatory in Germany. According to the decisions of the Federal States Committee of atomic energy for the relevant radiation protection ordinances the flat glass dosemeter may be used now as an official dosemeter by governmental services for individual monitoring also in the field of medical applications.

According to the PTB requirements for the type test, the relative overall uncertainty of measurement $G(H)$ is given by :

$$
G(H)=\sqrt{\sum_{i}\left(f_{\mathrm{ex}, i}\right)^{2}+Q^{2}+3 v(H)^{2}}
$$

here, $f_{\mathrm{ex}, i}$ are the extreme values of the change in response which is caused by the $i_{\text {th }}$ of nine different systematical uncertainties to be investigated, such as photon energy and direction of radiation incidence, $Q$ is the coefficient of nonlinearity and $v(H)$ the coefficient of variation of the dose measurement derived from a dosemeter batch. 
According to the PTB requirements, the maximum permissible value of the overall uncertainty $G_{\max }(H)$ is 0.3 for area dosemeters and 0.4 for personnel dosemeters. The pattern approval for the flat glass dosemeter resulting in a lowest and highest detectable dose of $H_{\min }=0.1 \mathrm{mSv}$ and $H_{\max }=8 \mathrm{~Sv}$ for glasses with pre-dose $<3 \mathrm{mSv}$ for a radiation incidence within a conus of $\alpha=60^{\circ}$, in comparison to the minimum requirements for a personnel dosemeter with $H_{\min }=0.2 \mathrm{mSv}, H_{\max }=2 \mathrm{~Sv}$ and $\alpha=45^{\circ}$.

As a result of the PTB type test, Figure 18 shows the coefficient of variation $v(H)$, the estimated overall uncertainty $G(H)$ and the maximum permissible overall uncertainty $G_{\max }(H)$ for a personnel dosemeter with $H_{\min }=0.2 \mathrm{mSv}$. At $0.1 \mathrm{mSv}$, the value of $v(H)$ is thus between $3 \%$ and $26 \%$ when flat glass dosemeters used in routine monitoring have pre-doses of 0.03 and $3 \mathrm{mSv}$, respectively.

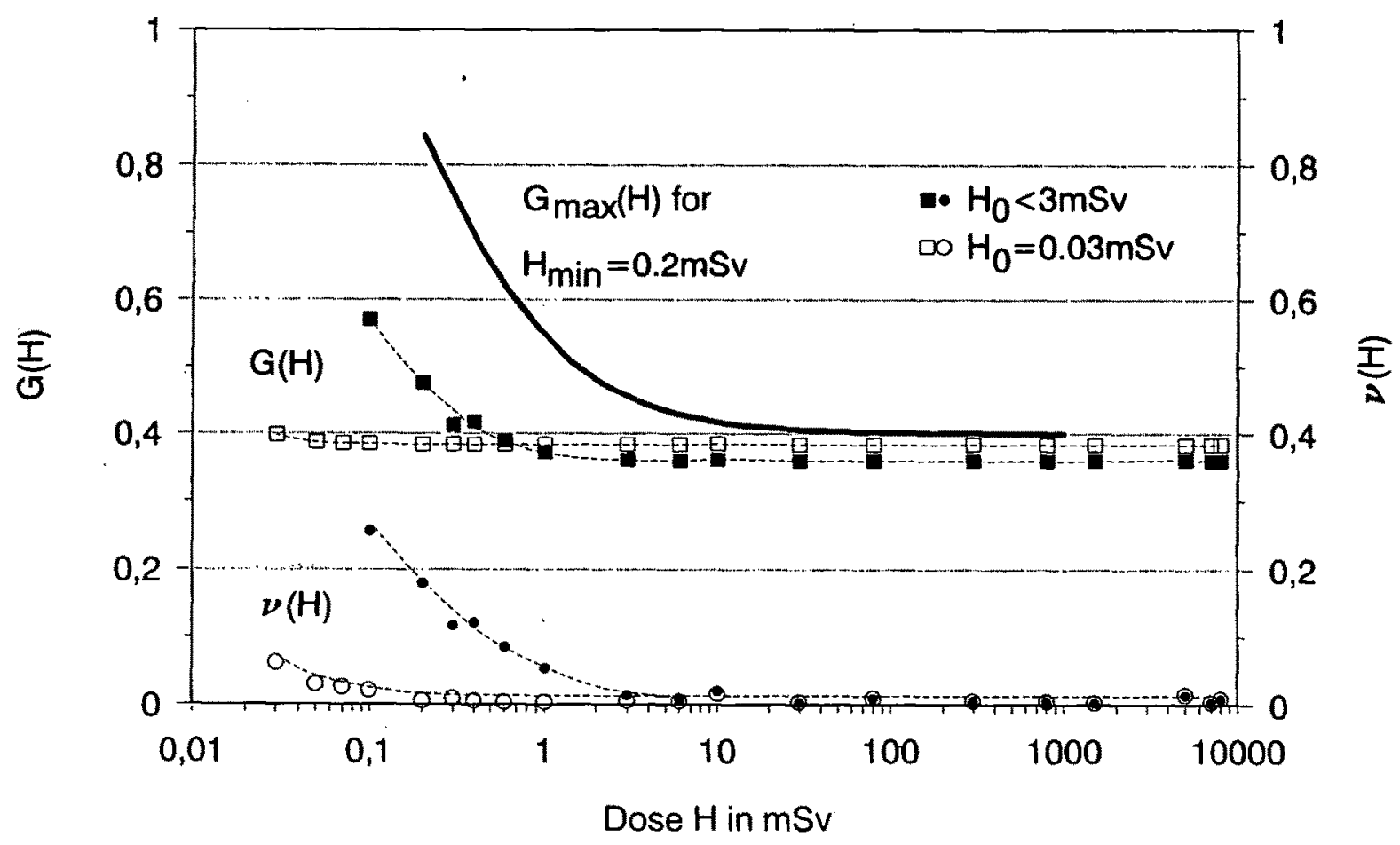

Fig. 18. - Maximum permissible overall uncertainty $G_{\max }(H)$ for a personnel dosemeter with $H_{\min }=0.2 \mathrm{MeV}$, overall uncertainty $G(H)$ of the flat glass dosemeter on the basis of pattern approval and coefficient of variation $v(H)$ for pre-doses between $0.03 \mathrm{mSv} \leq \mathrm{H}_{0}<3 \mathrm{mSv}$.

Incertitude globale maximale admissible $G_{\max }(H)$ pour un dosimètre individuel $\left(H_{\min }=0,2 \mathrm{MeV}\right)$; incertitude globale $\mathrm{G}(\mathrm{H})$ du verre dosimètre plan homologué avec un coefficient de variation $v(H)$ pour des pré-doses $0,03 m S v<H_{0}<3 m S v$.

\section{Results of routine monitoring}

In personnel monitoring on a monthly basis, glass dosemeters are generally able to measure small doses above $30 \mu \mathrm{Sv}$ with sufficient accuracy. Because the lowest detectable dose of thermoluminescence and film dosemeters has been 
found to be higher in routine monitoring, the results of different dosemeters agree sufficiently for higher exposures, but makes a comparison difficult in the dose range $0.1 \mathrm{mSv}$ and below [21].

In the case of personnel monitoring in areas of higher exposures at the Rossendorf Nuclear research center, the dose distribution (Fig. 19a) shows significantly high exposure in the range of $0.3-0.5 \mathrm{mSv}$ and for the 3 months of comparison and, in addition, workplace or working time dependent differences in the individual doses accumulated per month. Glass and film dosimeter results agree sufficiently for higher doses only.

As an example of routine monitoring at lower radiation levels, Figures $19 \mathrm{~b}$ and $\mathrm{c}$ show the frequency distribution of individual doses at KfK after subtraction of the natural background using for the presentation of the results dose intervals of $0.02 \mathrm{mSv}$ and $0.1 \mathrm{mSv}$ for a monthly (Fig. 19b) and an annual monitoring period (Fig. 19c), respectively. The low random uncertainty of the PLD system in the dose range below $0.1 \mathrm{mSv}$ may allow, mainly for annealed glasses, an interpretation of the results with more detail and higher accuracy if intervals of at least $0.04 \mathrm{mSv}$ are used instead of usually $0.2 \mathrm{mSv}$ above a threshold of $0.1 \mathrm{mSv}$.

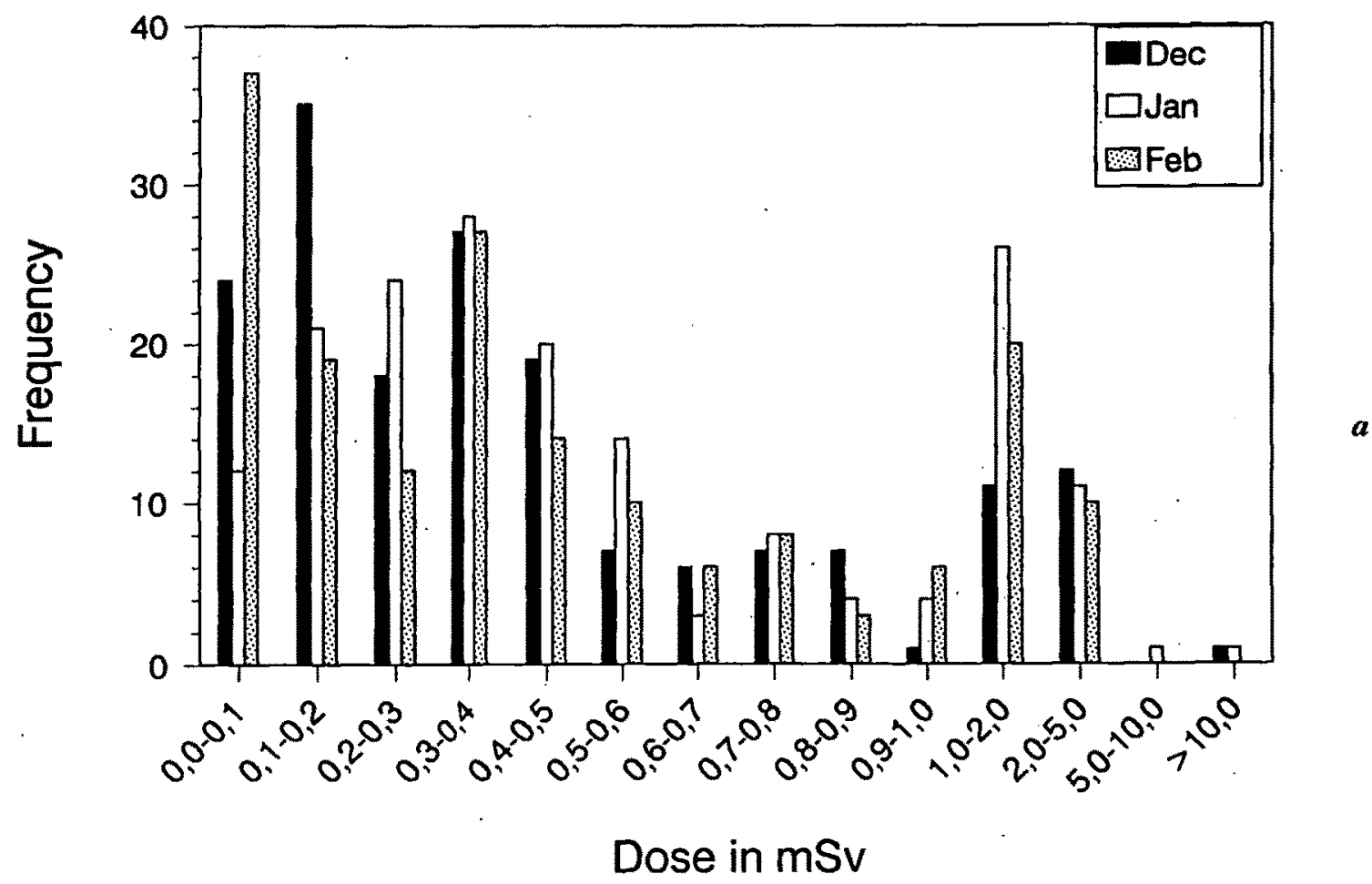



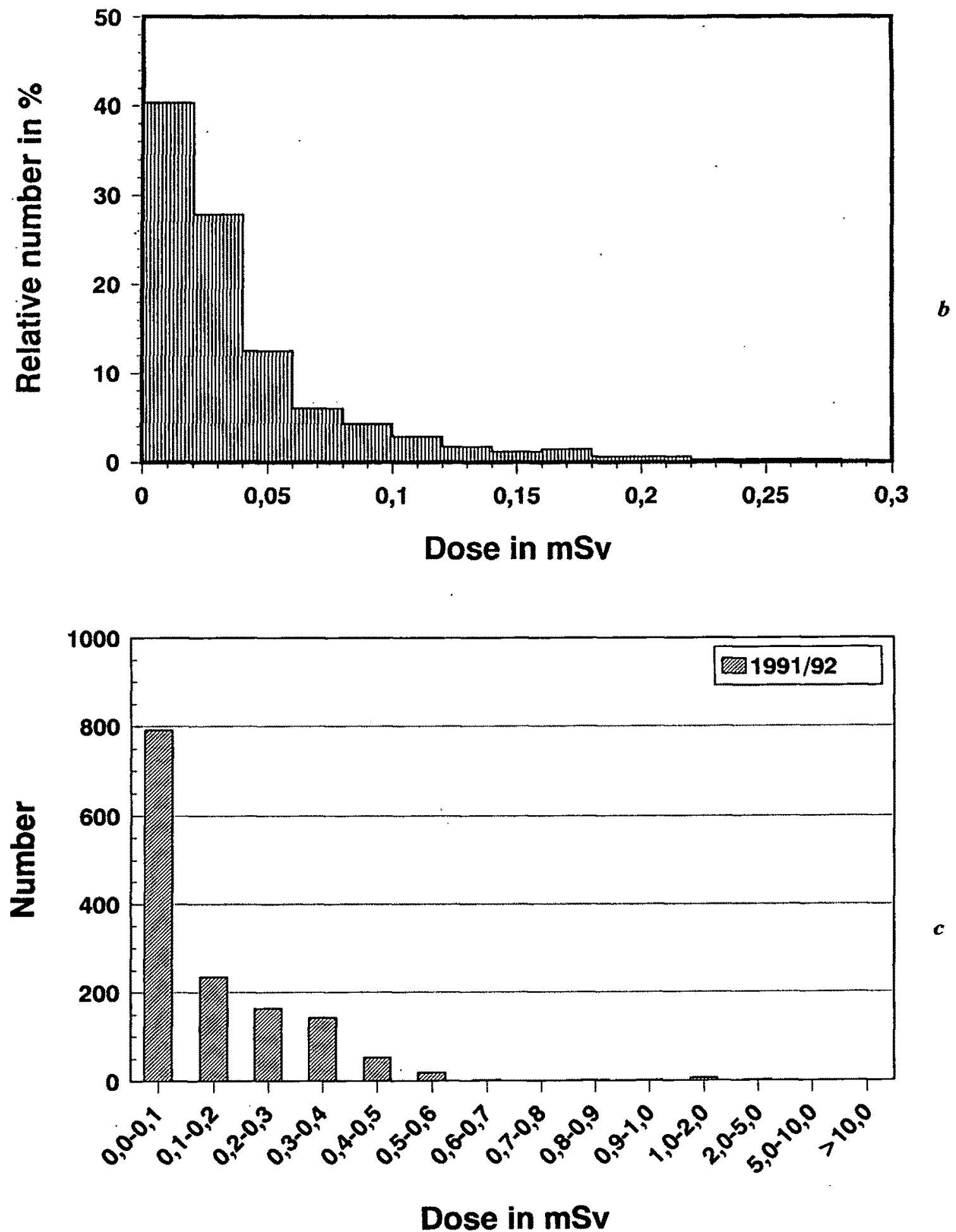

Fig. 19. - Frequency distribution of individual doses per month measured with flat PL dosemeters in routine monitoring, (a) at the Rossendorf Nuclear research centre for 1 month, (b) at KfK for 1 month, (c) at KfK for 6 months; total number of monitored persons : 1416.

Distribution de fréquence des doses individuelles mensuelles mesurées avec des dosimetres PL plans en surveillance de routine : a) au Centre de recherches de Rossendorf pendant 1 mois ; b) au KfK pendant 1 mois ; c) au KfK pendant 6 mois ; nombre de personnes surveillées : 1416. 
For the estimation of the annual dose, the limit of detection is given here mainly by the uncertainty in measuring or estimating the relevant natural background dose $H_{\text {nat }}$. In long-term personnel monitoring, for instance over a period of 6 months, the contribution of natural radiation $H_{\text {nat }}$ of about $0.4 \mathrm{mSv}$ can be measured separately by an annealed reference dosemeter. In this case, occupational exposures of about $0.1 \mathrm{mSv}$ can be monitored with an acceptable relative standard deviation of about $4 \%$ for an annealed glass and $20 \%$ for a glass which previously accumulated a dose of $3 \mathrm{mSv}$ (Fig. 20).

For personnel and environmental long-term monitoring, the accumulation period starts only with annealed glasses. In contrast to routine personnel dosimetry, here only the individual intrinsic pre-dose with an uncertainty of $\pm 1 \mu \mathrm{Sv}$ has to be subtracted from the readout resulting in a coefficient of variation of about $3 \%$ at $0.1 \mathrm{mSv}$ and $2 \%$ for two dosemeters. As compared to TL detectors, flat glass dosemeters used for environmental monitoring at KfK are more accurate in the dose measurement resulting in a lower scatter of the detector readings of two dosemeters exposed at the same location. In conclusion, with the advantages of low energy dependence, large photon energy range and low temperature effect, glass dosemeters may offer an excellent overall accuracy for 6-months monitoring period not found before with TLD systems.

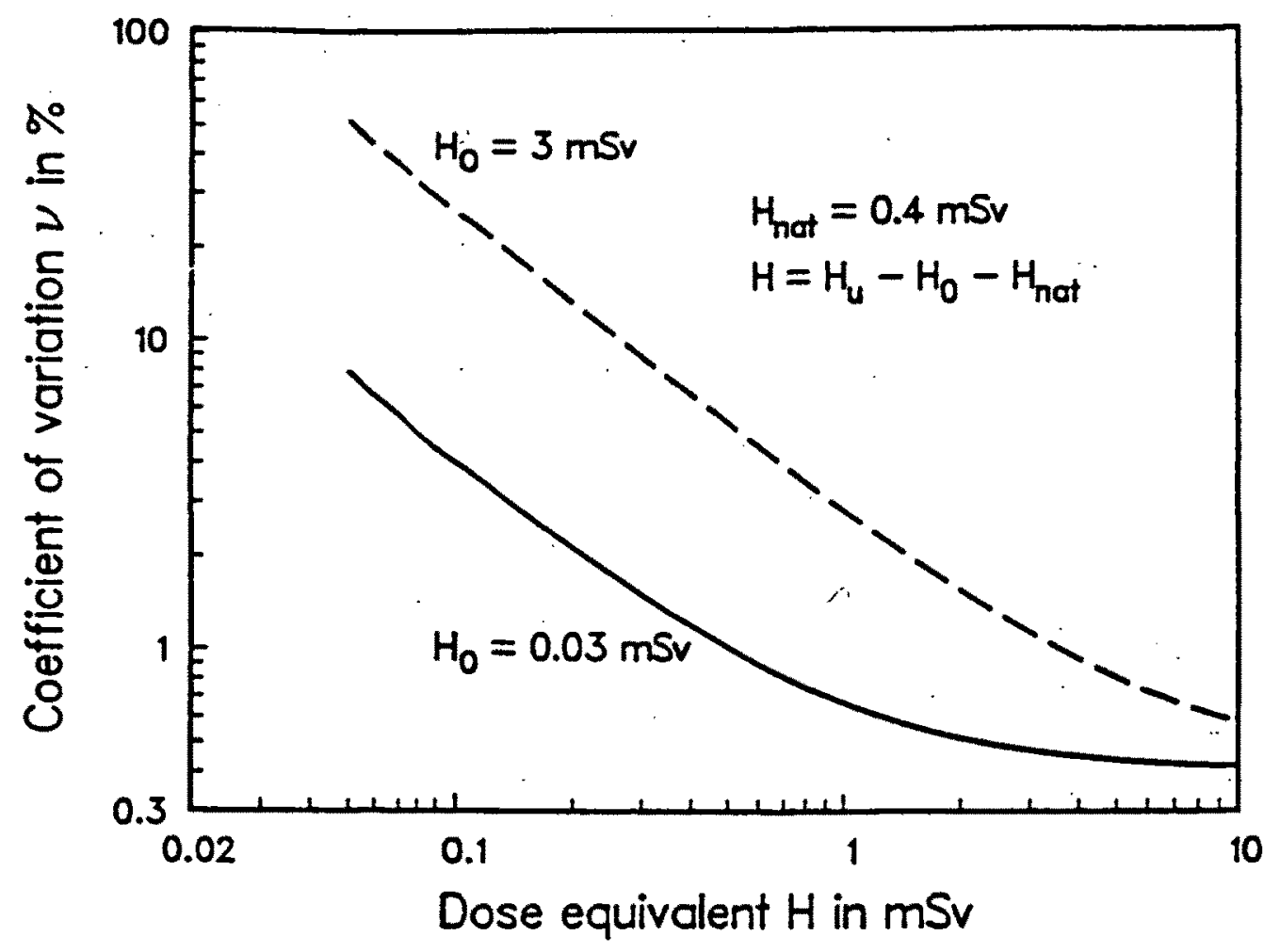

Fig. 20. - Random uncertainty of an individual dosemeter for a 6-month monitoring period using an unirradiated glass $(0.03 \mathrm{mSv})$ and a previously accumulated dose of $3 \mathrm{mSv}$. Incertitude, sur une période de 6 mois, pour un dosimètre individuel utilisant un verre non irradié $(0,03 \mathrm{mSv})$ et un verre pré-irradié à $3 \mathrm{mSv}$. 


\section{Conclusion}

The modern PLD system consisting of the flat one-element glass dosemeter and the commercially available readout system Toshiba FGD-10 has been found to be a suitable personnel and area dosemeter system for a wide photon energy range rivalled only by the best TLD systems which make use of four differently shielded detectors and a linear superposition of readouts.

Routine monitoring experience and participation at the IAEA intercomparison experiment resulted in an excellent long-term stability of the system with an accuracy of measurement in the order of $1 \%$ not obtained so far with other solid state dosimetry systems.

In comparison with other dosemeter systems, the PLD system should offer a low uncertainty of measurement in the $10 \mu \mathrm{Sv}$ dose range especially when annealed glasses are used. Combined with the remarkable long-term stability of the PLD system, longer monitoring periods of 6 or 12 months or even more may detect low levels of exposures in individual and environmental monitoring.

In routine monitoring, phosphate glass dosimetry is now comparable with thermoluminescence dosimetry in the fully automatic readout but superior in its glass specific properties, such as simplicity, stability of readout and calibration, good batch uniformity, individual pre-dose subtraction, insensitivity against ambient temperature and humidity effects and the capability of repeated readouts combined with a long-term dose accumulation.

For large-scale use of personnel dosimeters, both the PTB pattern approval and regular intercomparisons are mandatory for each dosimetry system in use by a dosemeter service. At the official dosimetry service at Karlsruhe, early in 1993, the new flat glass dosemeter superseded the old type of phosphate glass dosemeter in the spherical encapsulation which had been in use since 1964. The simultaneous indication of different dose quantities in a wide range of photon energy allows for a change from the exposure free in air, which until now has been the legal quantity in Germany, to the new ICRU quantity $H_{\mathrm{p}}(10)$. On the other hand, the existing exposure results may be transferred to $H_{\mathrm{p}}(10)$ at any time or conversely. 


\section{REFERENCES}

[1] AMBROSI P., NEUHAUS R., PIESCH E. - First experience with pattern approvals of dosimetry systems in Germany. In : Solid state dosimetry, 10 th international conference, Washington, DC, July 13-17, 1992. Radiat. Prot. Dosim., 1993, 47, 401-407.

[2] BARTHE J., BLANC D., COMMANAY L., TESSIER J.L., FRANCOIS H. - On the fluorescence decay of silver-activated glass dosemeters. Health Phys., 1970, 18, 573-575.

[3] BÖHM J., BUCHHOLZ C. - Results of the IAEA co-ordinated research program on intercomparison for individual monitoring, 1990-1991. In : Intercomparison of radiation dosemeters for individual monitoring (IAEA-TECDOC-704). Vienna : IAEA, 1993, 55-76.

[4] BURGKHARDT M., VILGIS M., PIESCH E., ISHIDOYA T., IKEGAMI T. - Modern automatic readout system for phosphate glass dosemeters using UV laser excitation. Radiát. Prot. Dosim., 1990, 34, 369-372.

[5] BURGKHARDT M., HERRERA R., PIESCH E. - Long-term fading experiment with different TLD systems. In : 5th International conference on luminescence dosimetry, Sao Paulo, February 14-17, 1977. Giessen : Justus Liebig Universität, Physikalisches Institut, 1977, 75-83.

[6] BURGKHARDT M., PIESCH E., VILGIS M. - Erprobung eines Phosphatglasdosimetriesystems mit gepulster UV-Laseranregung. Report KFK-5110, 1993.

[7] CHAPUIS A.M. - In : Technical recommendations for the use of radiophotoluminescence dosimetry in individual monitoring. Report EUR-5655, 1977.

[8] DÖRGER G., PITT E., SCHARMANN A. - An automatic radiophotoluminescence device using the UV pulse technique. In : 5th International conference on luminescence dosimetry, Sao Paulo, February 14-17, 1977. Giessen : Justus Liebig Universität, Physikalisches Institut, 1977, 114-121.

[9] HILLENKAMP F., REGULLA D.F. - Laser pulse excitation of radiation induced photoluminescence in silver-activated phosphate glasses. In : 3rd International conference on luminescence dosimetry, Risö, 11-14 Oct., 1971. Risö report n² 249, 1971, Pt II, 718-726.

[10] INTERNATIONAL ATOMIC ENERGY AGENCY (IAEA) - Personnel dosimetry systems for external radiation exposures (Technical report series ${ }^{\circ}$ 109). Vienna : IAEA, 1970.

[11] INTERNATIONAL COMMISSION ON RADIATION UNITS AND MEASUREMENTS (ICRU) - Determination of dose equivalents resulting from external radiation sources (ICRU report 39). Bethesda : ICRU, 1985.

[12] KASTNER J., EGGENBERGER D., LONGNECKER A., KING D., SCHUTT D. - UV laser excitation for ultra-senstivie photoluminescent dosimetry. In : Solid state and chemical radiation dosimetry in medicine and biology, Vienna, 3-7 Oct. 1966. Vienna : IAEA, 1967, 115-120.

[13] OMORI T., IKEGAMI T. AI T. - Fluoro-glass-dosimeter reader by $\mathrm{N}_{2}$ gas laser excitation. Toshiba Rev., 1984, 39, 247-250.

[14] PERRY J.A. - RPL dosimetry radiophotoluminescence in health physics. Bristol : A. Hilger, 1987.

[15] PIESCH E., BURGKHARDT B., FISCHER M., RÖBER H.G., UGI S. - Properties of radiophotoluminescent glass dosemeter systems using pulsed laser UV excitation. Radiat. Prot. Dosim., 1986, 17, 293-297.

[16] PIESCH E., BURGKHARDT B., VILGIS M. - Can individual dosemeters for the measurement of the directional dose equivalent $\mathrm{H}^{\prime}(10)$ indicate organ dose and the effective dose equivalent ? Radiat. Prot. Dosim., 1989, 28, 21-28.

[17] PIESCH E., BURGKHARDT B., VILGIS M. - Photoluminescent dosimetry - progress and present state of the art. Radiat. Prot. Dosim., 1990, 33, 215-226.

[18] PIESCH E., BURGKHARDT B., VILGIS M. - Performance of the new photoluminescent glass dosimetry system at the IAEA intercomparison 1990-1991 for individual monitoring. Radiat. Prot. Dosim. (in press). 
[19] PIESCH E., BURGKHARDT B., VILGIS M. - Developments in phosphate glass dosimetry for routine monitoring. In : Intercomparison of radiation dosemeters for individual monitoring (IAEA-TECDOC-704). Vienna : IAEA, 1993, 127-142.

[20] PIESCH E., BURGKHARDT B., VILGIS M. - Measurement of low photon exposures using a fully automatic phosphate glass dosimetry system with UV laser excitation. In : IRPA 8, Montreal, May 17-22, 1992. Montreal : International radiation protection association (IRPA), 1992, 1, 116-119.

[21] PIESCH E., BURGKHARDT B., VILGIS M. - Progress in phosphate glass dosimetry : experiences and routine monitoring with a modern dosimetry system. In : Solid state dosimetry, 10th international conference, Washington, DC, July 13-17, 1992. Radiat. Prot. Dosim., 1993, 47, 409-414.

[22] SCHNECKENBURGER H., REGULLA D., UNSÖLD E. - Time-resolved investigations of radiophotoluminescence in metaphosphate glass dosemeters. Appl. Phys., 1981, A26, 23-26.

[23] YOKOTA R., MUTO Y., KOSHIRO Y., SUGAWARA H. - New type of high-sensitive and soil-insensitive RPL glass dosimetry. In : 3rd International conference on luminescence dosimetry. Risö report n ${ }^{\circ} 249,1971$, Pt II, 709-717. 